Argonne

Liquid Salt - Very High Temperature Reactor: Survey of Sodium-cooled Fast Reactor Fuel Handling Systems for Relevant Design and Operating Characteristics

Nuclear Engineering Division 


\section{About Argonne National Laboratory}

Argonne is a U.S. Department of Energy laboratory managed by The University of Chicago

under contract W-31-109-Eng-38. The Laboratory's main facility is outside Chicago, at

9700 South Cass Avenue, Argonne, Illinois 60439. For information about Argonne,

see www.anl.gov.

\section{Availability of This Report}

This report is available, at no cost, at http://www.osti.gov/bridge. It is also available

on paper to the U.S. Department of Energy and its contractors, for a processing fee, from:

U.S. Department of Energy

Office of Scientific and Technical Information

P.O. Box 62

Oak Ridge, TN 37831-0062

phone (865) 576-8401

fax (865) 576-5728

reports@adonis.osti.gov

\section{Disclaimer}

This report was prepared as an account of work sponsored by an agency of the United States Government. Neither the United States Government nor any agency thereof, nor The University of Chicago, nor any of their employees or officers, makes any warranty, express or implied, or assumes any legal liability or responsibility for the accuracy, completeness, or usefulness of any information, apparatus, product, or process disclosed, or represents that its use would not infringe privately owned rights. Reference herein to any specific commercial product, process, or service by trade name, trademark, manufacturer, or otherwise, does not necessarily constitute or imply its endorsement, recommendation, or favoring by the United States Government or any agency thereof. The views and opinions of document authors expressed herein do not necessarily state or reflect those of the United States Government or any agency thereof, Argonne National Laboratory, or The University of Chicago. 
Liquid Salt - Very High Temperature Reactor: Survey of Sodium-cooled Fast Reactor Fuel Handling Systems for Relevant Design and Operating Characteristics

by

J.E. Cahalan and T.A. Taiwo

Nuclear Engineering Division, Argonne National Laboratory

March 31, 2006 


\section{TABLE OF CONTENTS}

Page

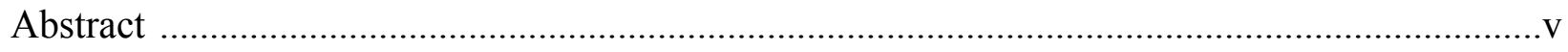

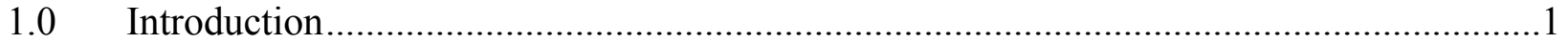

2.0 EBR-II Fuel Handling System ..................................................................................2

3.0 FFTF Fuel Handling System............................................................................

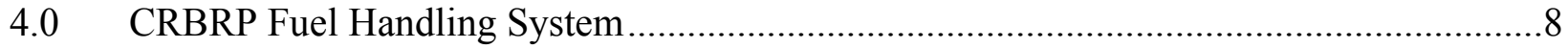

5.0 Discussion of LS - VHTR Fuel Handling System Design Considerations .....................11

5.1 Primary System Refueling Temperature.........................................................11

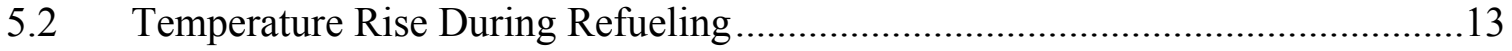

5.3 In-Vessel Fuel Handling Equipment Design and Fuel Restraint Design...............14

5.4 Sodium-Cooled Reactor Fuel Handling Design Requirements

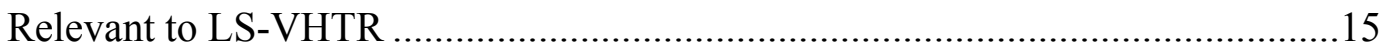

References

Appendix A FFTF Fuel Handling System: Summary Description .................................... 18

Appendix B CRBRP Fuel Handling System: Summary Description.....................................37 


\section{LIST OF FIGURES}

Page

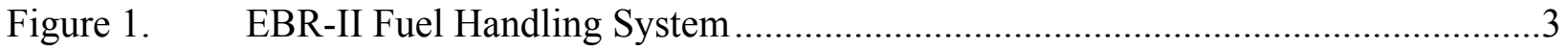

Figure 2. General Arrangement of FFTF Reactor Refueling Facilities .............................5

Figure 3. $\quad$ FFTF Closed Loop Ex-Vessel Machine (CLEM) ........................................6

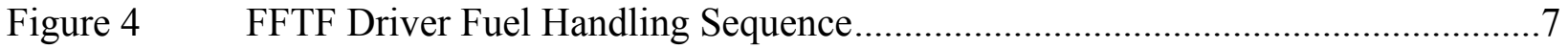

Figure 5. FFTF Driver Fuel Handling Sequence between

Interim Decay Storage and Reactor Vessel ..................................................

Figure 6. CRBRP Reactor Refueling System............................................................

Figure 7. CRBRP Reactor Vessel Head Rotating Plugs ................................................10

Figure 8. Thermal Profile for FFTF Fuel and Test Assemblies Handling (SDD-41) ..........12

Figure 9. Temperature Rise per Unit Time as a Function of Cooling Time ......................14 


\title{
LIQUID SALT - VERY HIGH TEMPERATURE REACTOR: SURVEY OF SODIUM-COOLED FAST REACTOR FUEL HANDLING SYSTEMS FOR RELEVANT DESIGN AND OPERATING CHARACTERISTICS
}

by

\author{
J. E. Cahalan and T. A. Taiwo
}

\begin{abstract}
The design and performance characteristics of Experimental Breeder Reactor-II (EBR-II), Fast Flux Test Facility (FFTF), and Clinch River Breeder Reactor Plant (CRBRP) fuel handling systems are reviewed for relevance to the proposed Liquid Salt - Very High Temperature Reactor (LS-VHTR). Descriptions of the EBR-II, FFTF, and CRBRP fuel handling systems and operational procedures are summarized. Features of these systems relevant to the Liquid Salt Very High Temperature Reactor (LS - VHTR) are discussed. Unique design features and operating characteristics of LS - VHTR that require additional engineering attention are noted, along with suggested design resolutions.
\end{abstract}




\subsection{Introduction}

The design and performance characteristics of Experimental Breeder Reactor-II (EBR-II), Fast Flux Test Facility (FFTF), and Clinch River Breeder Reactor Plant (CRBRP) fuel handling systems have been reviewed for relevance to the proposed Liquid Salt - Very High Temperature Reactor (LS-VHTR) (1). EBR-II, FFTF, and CRBRP all used liquid sodium as coolant. Fuel handling operations were performed in a closed primary system at high temperatures sufficient to maintain coolant liquidity. This summary provides brief descriptions of the fuel handling systems and their operation, and a discussion of design requirements relevant to LS-VHTR.

The fuel handling system designs for EBR-II, FFTF, and CRBRP reflect the requirements imposed by the individual facility missions and reactor system designs. EBR-II was intended as a developmental breeder reactor power station prototype; FFTF was designed as an irradiation test facility for fuels and materials; and CRBRP was proposed as a demonstration commercial breeder reactor power station.

The pool-type EBR-II design features a large primary system tank containing the reactor and all primary coolant systems, including the reactor, the pumps, and the intermediate heat exchanger. The EBR-II primary tank also contains a spent-fuel storage basket that can hold a discharge fuel batch for an extended period (typically 100 days) of decay heat cool-down. The provision for invessel spent fuel storage simplifies ex-vessel handling and storage requirements.

The FFTF testing mission imposes requirements for relatively frequent refueling and handling of large test components, as well as handling of standard reactor fuel assemblies. FFTF was designed as a loop-type primary system, with the reactor in a vessel connected to the pumps and intermediate heat exchangers by piping. The configuration limits in-vessel spent-fuel storage capability, and places additional requirements on ex-vessel fuel handling equipment, relying on discharge to ex-vessel storage for routine cool-down operations.

CRBRP was designed and licensed, but not constructed. However, it was designed with strong reliance on FFTF experience, taking into account the CRBRP mission of power production, in contrast to the FFTF mission of fuel testing. The CRBRP mission requires relatively infrequent refueling outages of minimum duration, during which a large fraction of the core is refueled. The loop-type CRBRP primary system design provides only minimal in-vessel fuel storage; routine operations require immediate spent fuel discharge and transfer to ex-vessel storage for cool-down.

Temperature requirements on liquid-metal reactor fuel handling systems designs are typically set on the basis of maintaining spent fuel integrity (or test sample integrity for the case of FFTF), and operational temperature requirements vary depending on mission. Actual system capabilities are set by materials compatibility and strength characteristics. In liquid sodium systems, the structural material is typically stainless steel (316 or 304) which has excellent strength properties to $550^{\circ} \mathrm{C}$ and beyond.

For the LS - VHTR, high strength alloys with temperature capabilities to $750^{\circ} \mathrm{C}$ are proposed. 


\subsection{EBR-II Fuel Handling System (Refs. 2, 3)}

The EBR-II fuel handling system is designed to facilitate loading of fresh fuel into the reactor and removal of irradiated fuel from the reactor to the adjacent fuel cycle facility. The design of the EBR-II fuel handling system is described in Ref. 2.

The EBR-II fuel handling system is depicted in Figure 1, which shows the reactor, the fuel gripper and hold-down mechanisms, the transfer arm, the storage basket, and the fuel unloading machine.

The EBR-II reactor is enclosed within an inner vessel that caused hot coolant to flow from the reactor outlet plenum through a pipe to the intermediate heat exchanger (IHX), where heat is transferred to the secondary coolant. Cold primary coolant exiting the IHX flows into the large cold pool inside the primary tank, which holds all the primary coolant, the reactor, the IHX, and two primary coolant pumps. The primary pumps draw suction from the cold pool and discharge through piping to the reactor inlet plenum at the bottom of the vessel. Coolant then flows upward through the reactor to the outlet plenum.

For refueling operations, the control rod drive shafts are disconnected and lifted, and the reactor vessel cover is raised, as shown in Figure 1. The control rod drives and reactor cover lifting mechanisms are mounted on the smaller of two rotating plugs in the primary tank cover. Also mounted on the small rotating plug is the fuel gripper mechanism, which is capable of being positioned directly above any of the reactor fuel subassembly locations. To remove a subassembly, the gripper is lowered to the reactor where it grasps the subassembly to be lifted. Concurrently, the hold-down mechanism is lowered to prevent inadvertent extraction or movement of subassemblies adjacent to the gripped subassembly. The gripper drive mechanism raises the subassembly to be discharged, and plugs are rotated into a position where the transfer arm mechanism could grasp the subassembly. During plug rotations, the hold-down mechanism provides subassembly bottom support, in addition to top support by the gripper mechanism.

The manually-operated transfer arm rotates to locate the subassembly above one of three rows of positions in the storage basket, which rotated to provide correct positioning. To insert the subassembly into the storage basket, the transfer arm mechanism lowers the subassembly to start the insertion process, and the storage basket is raised to seat the subassembly. The transfer arm releases the subassembly, and the storage basket then lowers to storage position.

Irradiated subassemblies in the storage basket are cooled by natural circulation of primary tank coolant until decay heat falls to a level acceptable for transfer out of the primary tank.

Irradiated subassembly transfers to the fuel cycle facility from the storage basket are conducted during reactor power operation. The transfer arm is used to remove a subassembly from the storage basket and move it to a location where it is grasped by the fuel unloading machine gripper. The fuel unloading machine raises the subassembly first to a dripping elevation, next to an argon blowing elevation, and finally into a shielded, argon-cooled coffin through a transfer port in the primary tank cover. The rail-mounted fuel unloading machine then travels to the inter-building transfer station, where it lowers the subassembly into a second, inter-building 


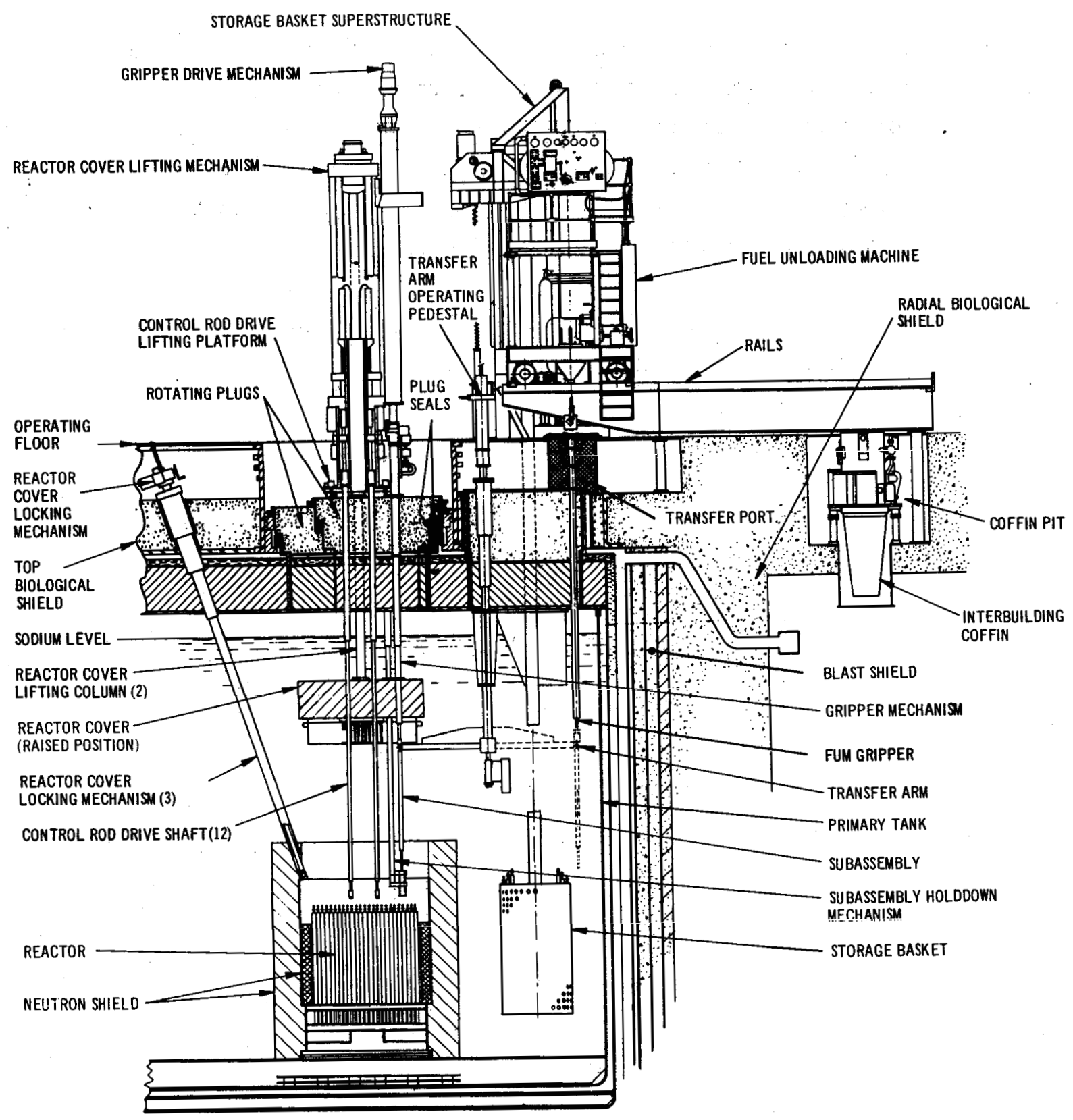

Figure 1. EBR-II Fuel Handling System.

coffin, also cooled by argon. This coffin subsequently travels to the fuel cycle facility. During all fuel handling operations, the maximum fuel pin temperature is maintained below $1200^{\circ} \mathrm{F}$ $\left(649^{\circ} \mathrm{C}\right)$.

Loading of fresh fuel is accomplished with the inverse operation. Fuel subassemblies loaded into the reactor are first heated to $450^{\circ} \mathrm{F}\left(232^{\circ} \mathrm{C}\right)$ in the fuel unloading machine prior to insertion into the primary tank sodium, which is maintained at $700^{\circ} \mathrm{F}\left(371^{\circ} \mathrm{C}\right)$. 


\subsection{FFTF Fuel Handling System (Ref. 4,5)}

The FFTF Reactor Refueling System includes facilities for the receipt, conditioning, storage, installation in and removal from the core of all core components (driver fuel assemblies, control assemblies) and test assemblies that are routinely removable. The Reactor Refueling System handles three types of core assemblies: 12-ft assemblies such as Driver Fuel; 40-ft assemblies such as Fuels Open Test Assemblies (FOTA); and 40-ft assemblies such as Materials Open Test Assemblies (MOTA).

The design of the FFTF fuel handling system is described in Ref. 4, and the system design requirements are given in Ref. 5. An overall plan view of the FFTF reactor refueling facilities is shown in Figure 2.

The principal ex-reactor component is the Closed Loop Ex-Vessel Machine (CLEM) shown in Figure 3. The CLEM loads all components into the reactor and removes all components from the reactor through one of three fuel transfer ports in the reactor vessel top cover.

The in-reactor components consist of three In-Vessel Handling Machines plus the three In-Vessel Storage Modules.

In the handling of twelve-foot assemblies such as driver fuel (Figures 4 and 5), an incoming assembly is first lowered by the crane into one of the two Core Component Conditioning Stations. In this station, the assembly is flooded with argon and heated to approximately $450^{\circ} \mathrm{F}\left(232^{\circ} \mathrm{C}\right)$. The assembly is then picked up by the Bottom Loading Transfer Cask and is transported, in an argon atmosphere, to the Interim Decay Storage Vessel. The assembly is then lowered into a sodium-filled Core Component Pot in the Interim Decay Storage Vessel. The assembly is held in Interim Decay Storage in liquid sodium at $500^{\circ} \mathrm{F}\left(260^{\circ} \mathrm{C}\right)$ to $600^{\circ} \mathrm{F}$ $\left(316^{\circ} \mathrm{C}\right)$ until the reactor is shut down for refueling.

At the shut-down reactor, the plug is removed from the Fuel Transfer Port and an adapter and floor valve are installed on the port. The control rod drive shafts are also disconnected, and the Instrument Trees are moved to their stored positions.

The CLEM then picks up the Core Component Pot containing the assembly, transports it to the reactor, and lowers it into an in-vessel storage module through the Fuel Transfer Port.

The next objective in the handling sequence is placing the assembly into the reactor core. First, the In-Vessel Handling Machine (IVHM) removes a spent assembly from the core and places it into an in-vessel storage module position. The IVHM then removes the new assembly from the Core Component Pot and places the new assembly into the core. Finally, the IVHM removes a spent assembly from the in-vessel storage module and places it into the Core Component Pot. The CLEM then picks up the Core Component Pot with contained spent assembly and places the Core Component Pot into the Interim Decay Storage Vessel. After a suitable decay period, the Bottom Loading Transfer Cask picks up the spent assembly and transfers it out of containment to the Fuel Storage Facility. 
Before reactor startup, the In-Vessel Handling Machines are placed in their "stored" positions in the reactor. The Instrument Trees and Control Rod Shafts are restored to poweroperation status, the adapter and floor valve are removed and the Fuel Transfer Port is sealed with its plug.

A more detailed description of the FFTF fuel handling system design, equipment, and operations is included in Appendix A.

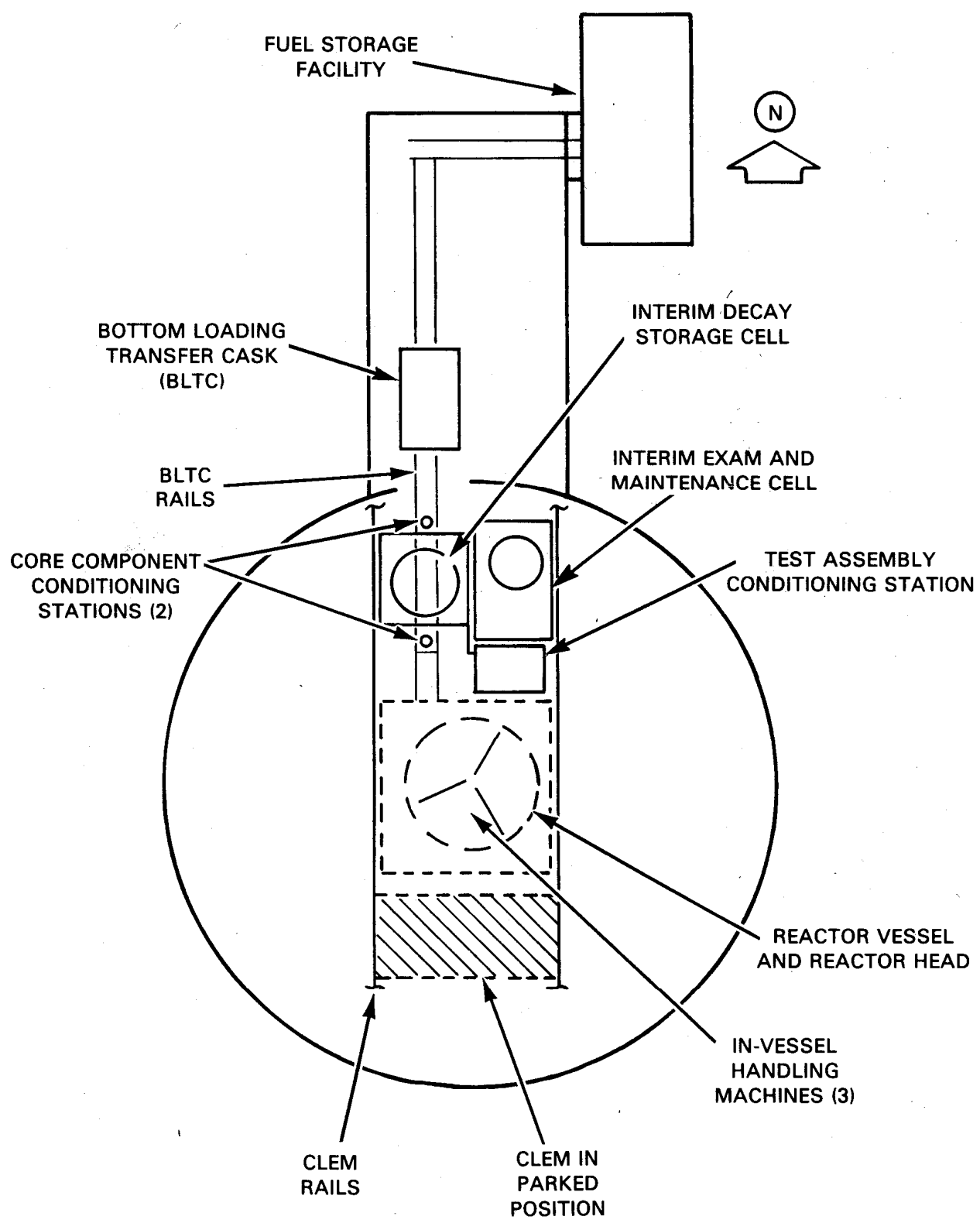

Figure 2. General Arrangement of FFTF Reactor Refueling Facilities. 


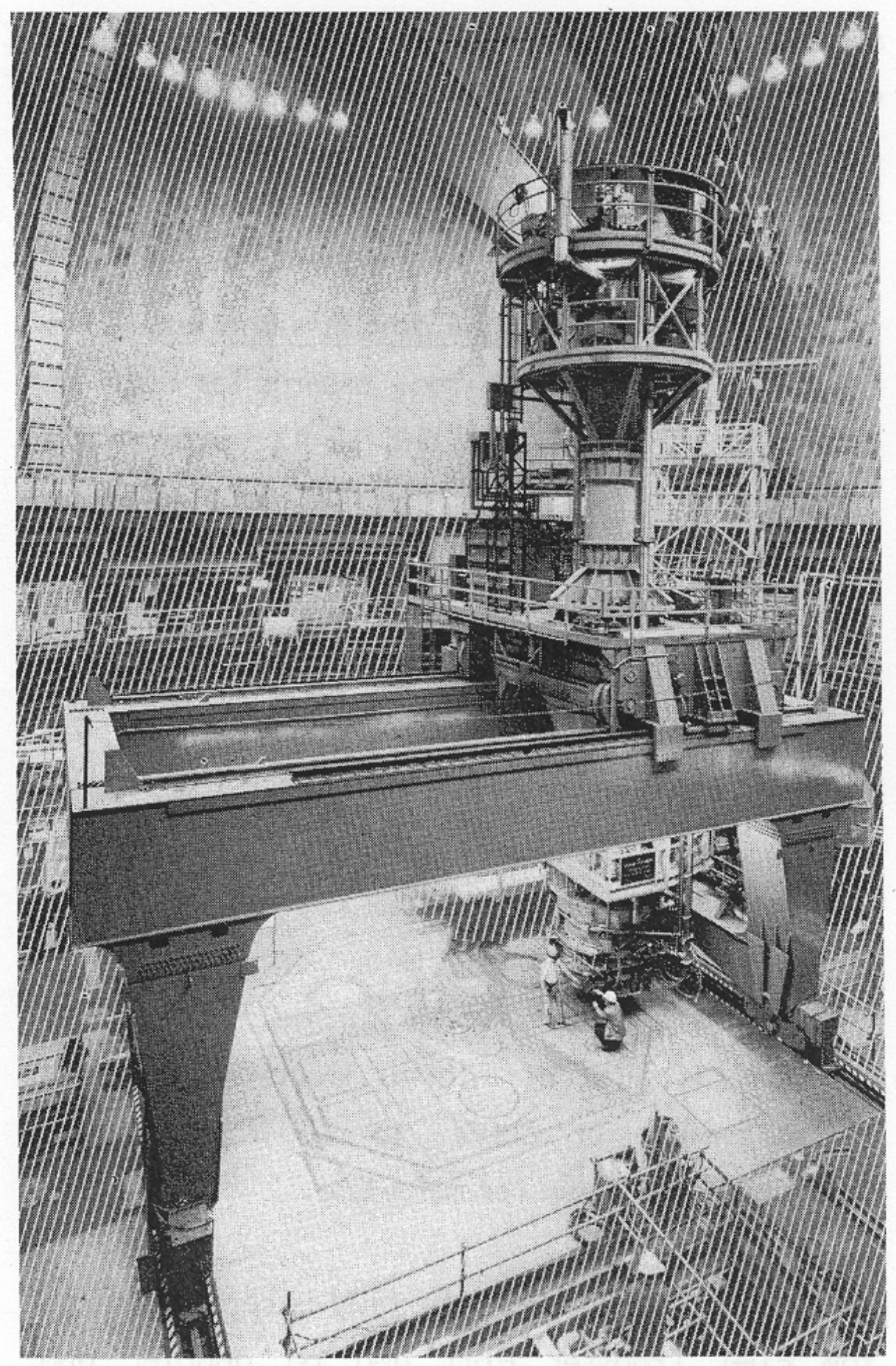

Figure 3. FFTF Closed Loop Ex-Vessel Machine (CLEM). 


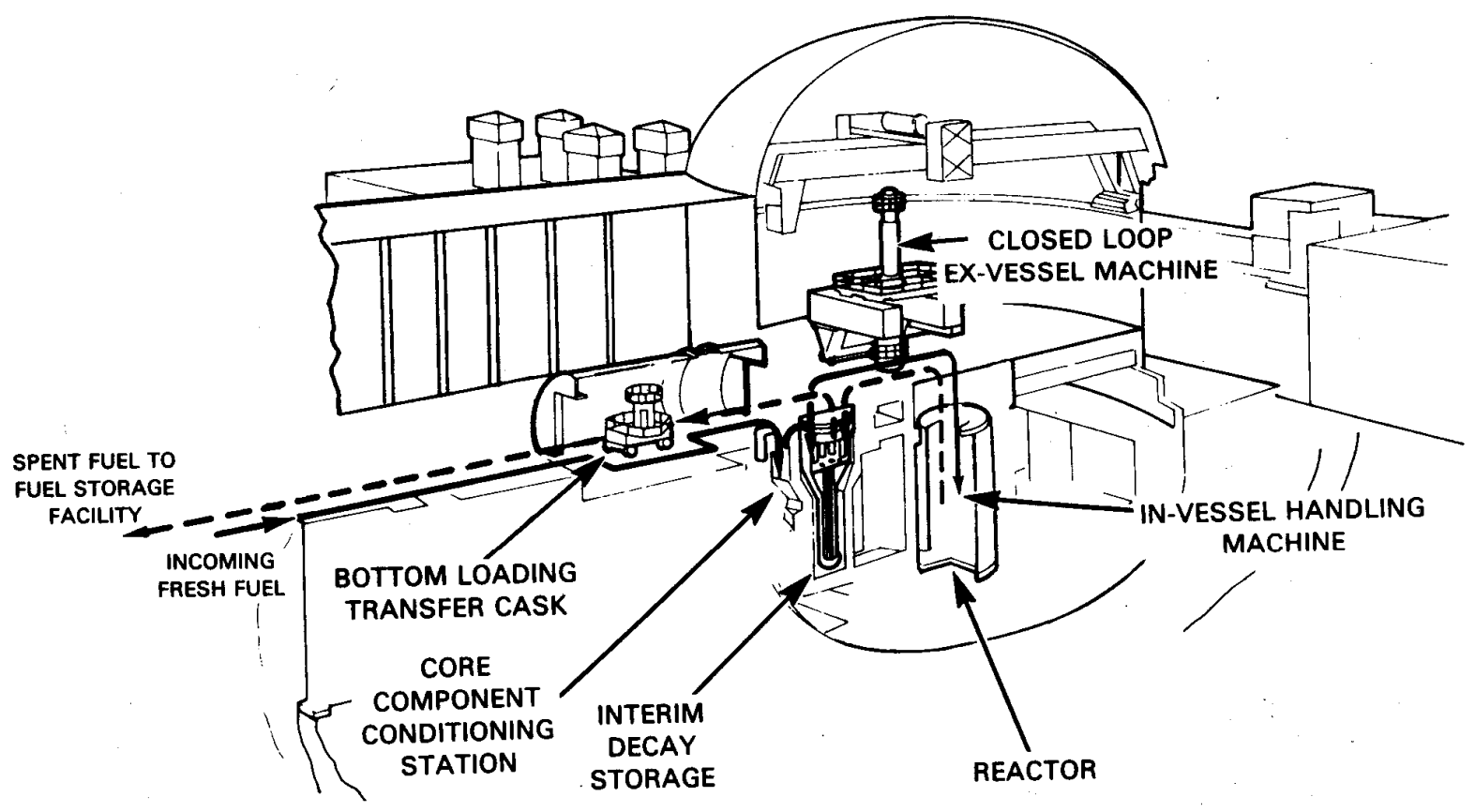

Figure 4. FFTF Driver Fuel Handling Sequence.

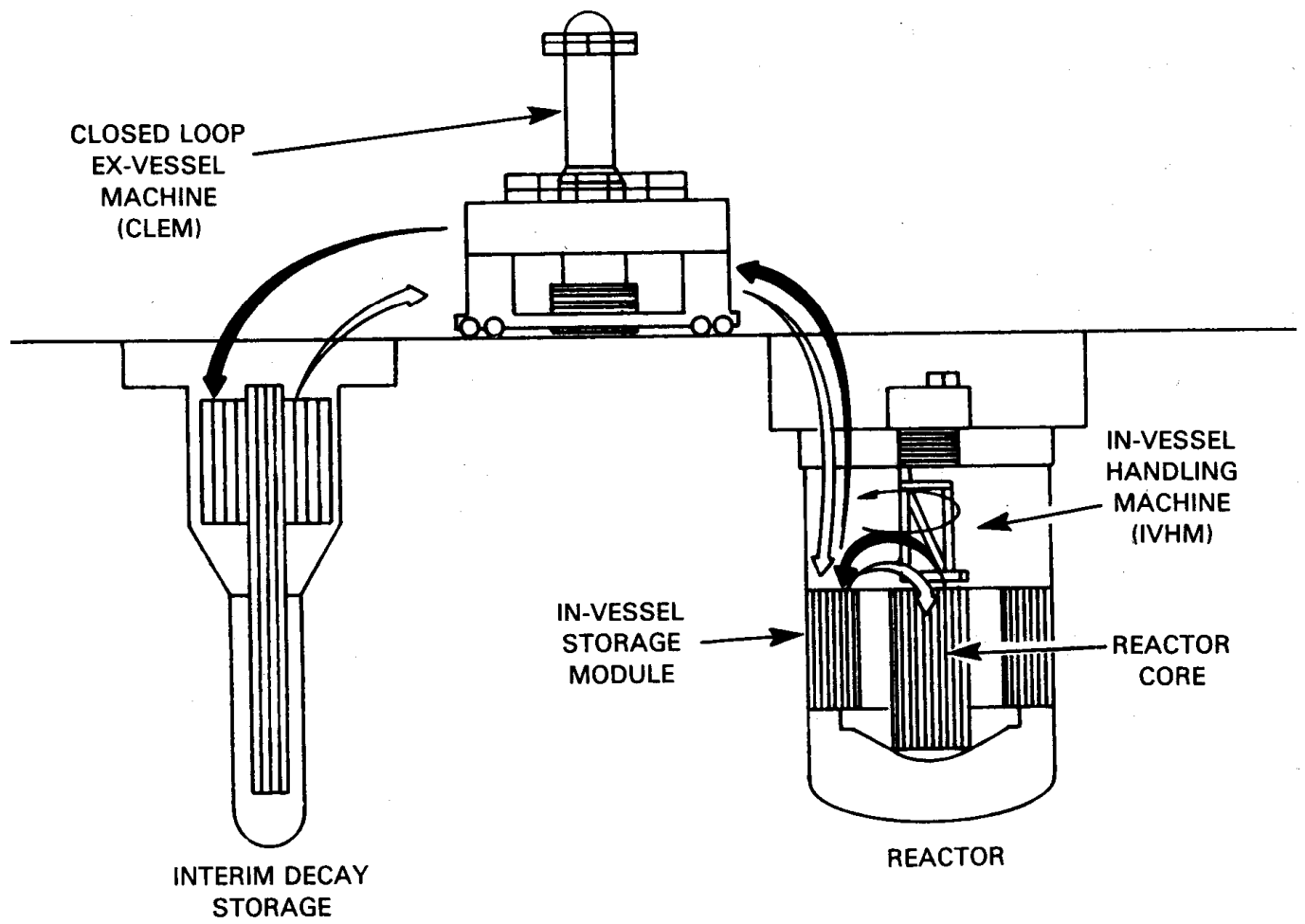

Figure 5. FFTF Driver Fuel Handling Sequence between Interim Decay Storage and Reactor Vessel. 


\subsection{CRBRP Fuel Handling System (Refs. 6, 7, 8)}

The CRBRP fuel handling system provides for replacement of fuel, blanket, control, reflector, and restraint assemblies. The system consists of the facilities and equipment needed to accomplish the normal scheduled refueling operations, as well as all other functions incident to handling of core components. Refueling operations involve transfer of core components between positions within the reactor vessel, and between the reactor and the ex-vessel storage tank (EVST). Refueling operations can be accomplished only with the reactor shut down.

A view of the fuel handling system general arrangement is shown in Figure 6. New fuel assemblies arrive at the plant in shielded and cushioned containers. These core components are unloaded and inspected in a shielded new fuel handling facility located in the reactor service building (RSB). Upon acceptance of a core component, it is stored in a sub-critical array in a storage facility located in the floor of the new fuel handling facility.

In preparation for the refueling cycle, new fuel assemblies are removed from the storage facility in a shielded transfer machine and inserted into a gas filled thimble in EVST. During the course of this operation, the air atmosphere in the shield transfer cask is exchanged for an inert, dry argon atmosphere which is compatible with the liquid sodium environment in the EVST. The new core components are loaded into the EVST at $475^{\circ} \mathrm{F}\left(246^{\circ} \mathrm{C}\right)$ until a reactor reload worth of fuel has been accumulated for refueling.

After the reactor is shut down, the ex-vessel transfer machine (EVTM) transfers a new fuel assembly, in a sodium filled core component pot (CCP), from the EVST to the reactor through a 44 ' 6 " hatch in the reactor containment building (RCB) wall. When the new fuel assembly arrives at the reactor, it is discharged from the EVTM into a transfer position on the periphery of the reactor core.

At this point, the new core component is available for handling by the in-vessel transfer machine (IVTM). The IVTM withdraws a spent fuel assembly from its position in the reactor core and deposits it into an empty CCP in a transfer position. The IVTM then picks up a new fuel assembly from the transfer position and inserts the assembly into position in the reactor core. Horizontal motion of the IVTM is accomplished by means of triple rotating plugs mounted in the reactor head (See Figure 7). By rotating these plugs in sequence, the IVTM, which is a simple straight pull tubular device mounted on a port in the inner-most rotating plug, can be indexed over any core or transfer position in the reactor.

When a spent core component is available in a transfer position, the EVTM withdraws the component in a CCP from the reactor vessel and transfers it to the EVST. The EVTM mates to a port in the large rotating plug for access to the fuel transfer positions inside the reactor vessel. After a suitable decay period, spent fuel can be removed from the EVST and prepared for shipment from the plant.

A more detailed description of the CRBRP fuel handling system design, equipment, and operations is included in Appendix B. 


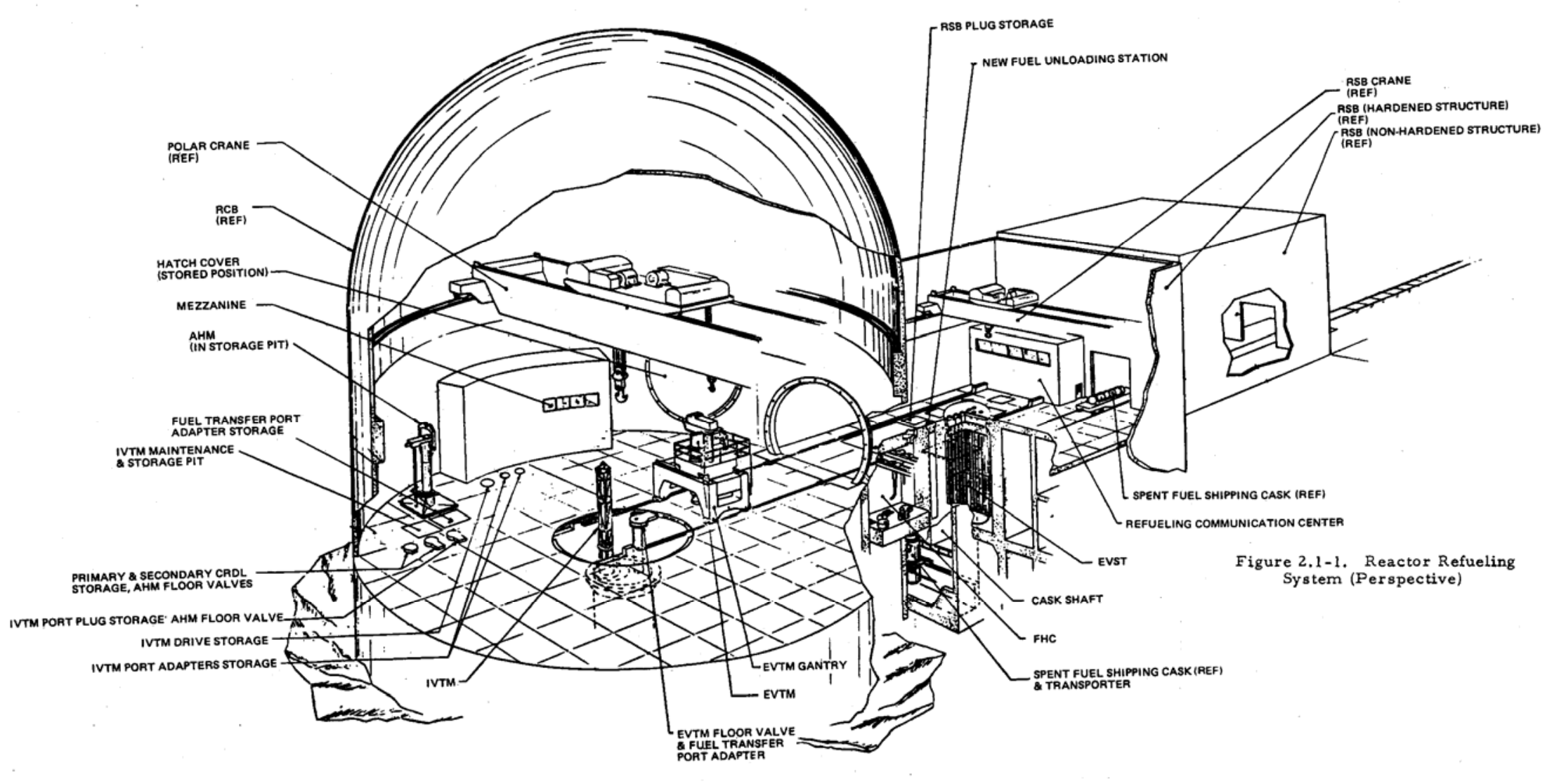

Figure 6. CRBRP Reactor Refueling System. 


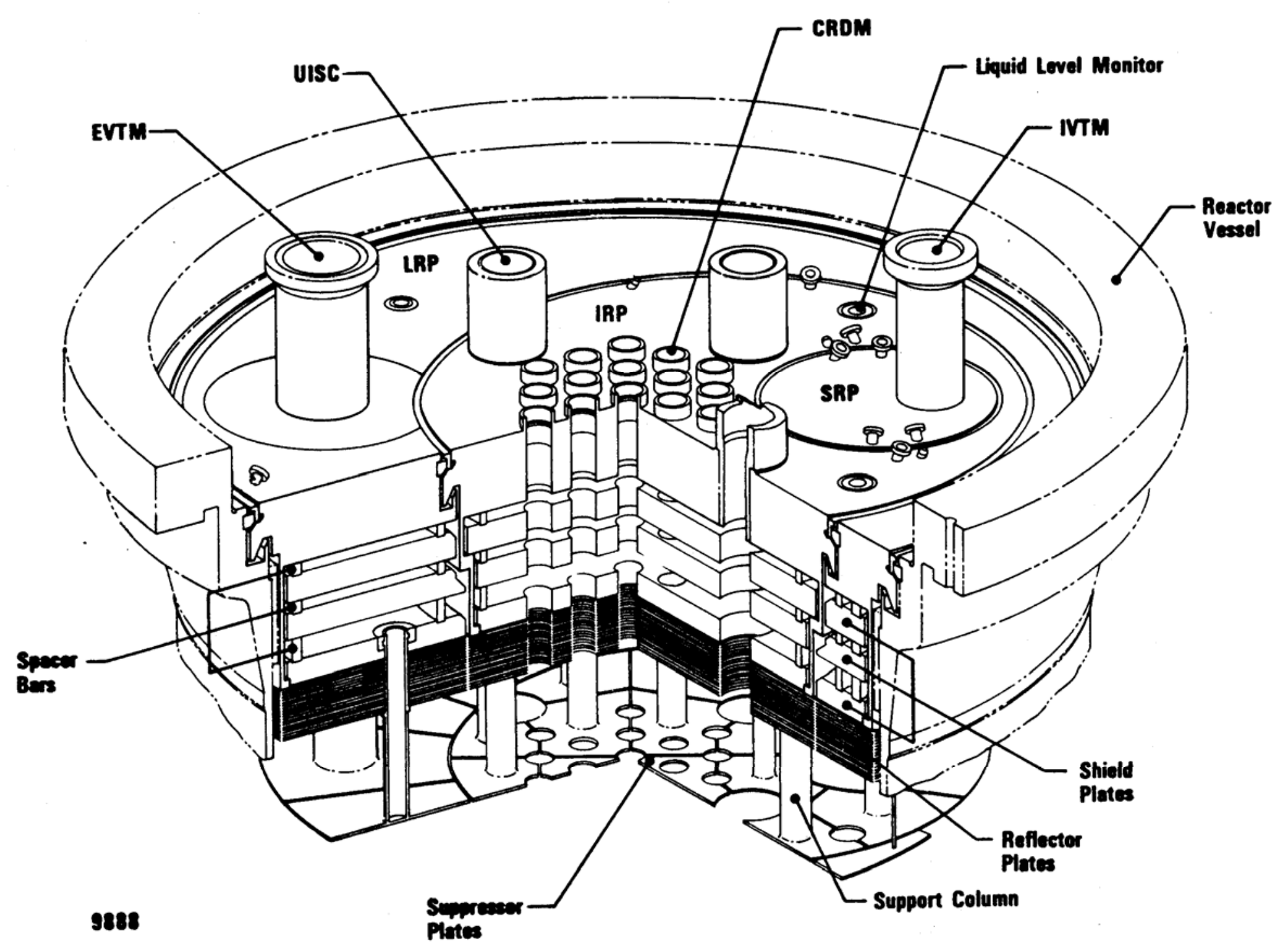

Figure 7. CRBRP Reactor Vessel Head Rotating Plugs. 


\subsection{Discussion of LS - VHTR Fuel Handling System Design Considerations}

This section provides discussions of LS - VHTR fuel handling system design considerations. In these discussions, it is assumed that the LS - VHTR reactor system design is described in Ref. 1.

\subsection{Primary System Refueling Temperature}

The high melting temperature of the coolant salts considered for LS - VHTR has been noted in earlier reviews as a feasibility issue for the refueling operation. This issue prompted a review of the EBR-II, FFTF, and CRBRP liquid metal reactor designs, since these designs also feature fuel handling at high temperatures. In addition, these systems required that fuel be handled in a closed system by remote techniques without direct visualization, in contrast to Light Water Reactor (LWR) fuel handling performed on an open system with direct viewing. The history of successful fuel handling at EBR-II and FFTF, as well as at international liquid sodium reactors, has proven the feasibility of remote fuel handling in closed systems at high temperature.

This survey of the EBR-II, FFTF, and CRBRP fuel handling design, operation, and experience has shown that the temperature at which fuel handling was conducted in these systems was dictated by design choices. For example, in EBR-II, fuel handling was conducted at $700^{\circ} \mathrm{F}$ $\left(371^{\circ} \mathrm{C}\right)$ because this was the design bulk temperature for the primary tank environment, the normal operating reactor coolant inlet temperature. This temperature was selected to provide margin above the coolant melting temperature $\left(98^{\circ} \mathrm{C}\right)$ in cold (peripheral, low flow) locations within the large primary tank of EBR-II. Fuel handling at this temperature is feasible because the structural materials used in EBR-II, primarily 304 and 316 stainless steels, have very good strength characteristics up to the range of $550^{\circ} \mathrm{C}$ and above. (The normal operating outlet temperature of EBR-II is $473^{\circ} \mathrm{C}$ ).

In contrast, the loop-type FFTF primary system design has a compact reactor vessel that does not have the large coolant volumes subject to stratification and flow stagnation like EBR-II. Hence the fuel handling temperature is not based on prevention of coolant freezing, since this is less of an issue in the FFTF design, but rather upon maximum allowable fuel temperatures during refueling. This criterion arises because of the fuel testing mission of FFTF, and the need to preserve test fuel integrity after irradiation. Figure 8 shows a specified fuel assembly thermal profile during FFTF fuel handling operations from SDD-41 (Ref. 5). Note that short term assembly temperatures (cladding temperatures) as high as $1000^{\circ} \mathrm{F}\left(538^{\circ} \mathrm{C}\right)$ are allowed during fuel handling. (For comparison, the coolant temperature range in FFTF during normal operation is $360^{\circ} \mathrm{C}$ to $503^{\circ} \mathrm{C}$ ). The normal recommended fuel assembly refueling temperatures range is $400^{\circ} \mathrm{F}$ minimum $\left(204^{\circ} \mathrm{C}\right)$ to $480^{\circ} \mathrm{F}\left(249^{\circ} \mathrm{C}\right)$.

Based on liquid sodium reactor design and operating experience, the process for determining the recommended fuel handling temperature for LS - VHTR should be based on assessment of 1) thermal-hydraulic studies to determine the minimum acceptable temperature margin above the coolant melting temperature to maintain coolant flow in natural circulation during refueling, 2) stress analysis of metallic structure temperatures (both reactor vessel structure and in-vessel fuel handling machine structure) required to maintain acceptable margins below material design basis 


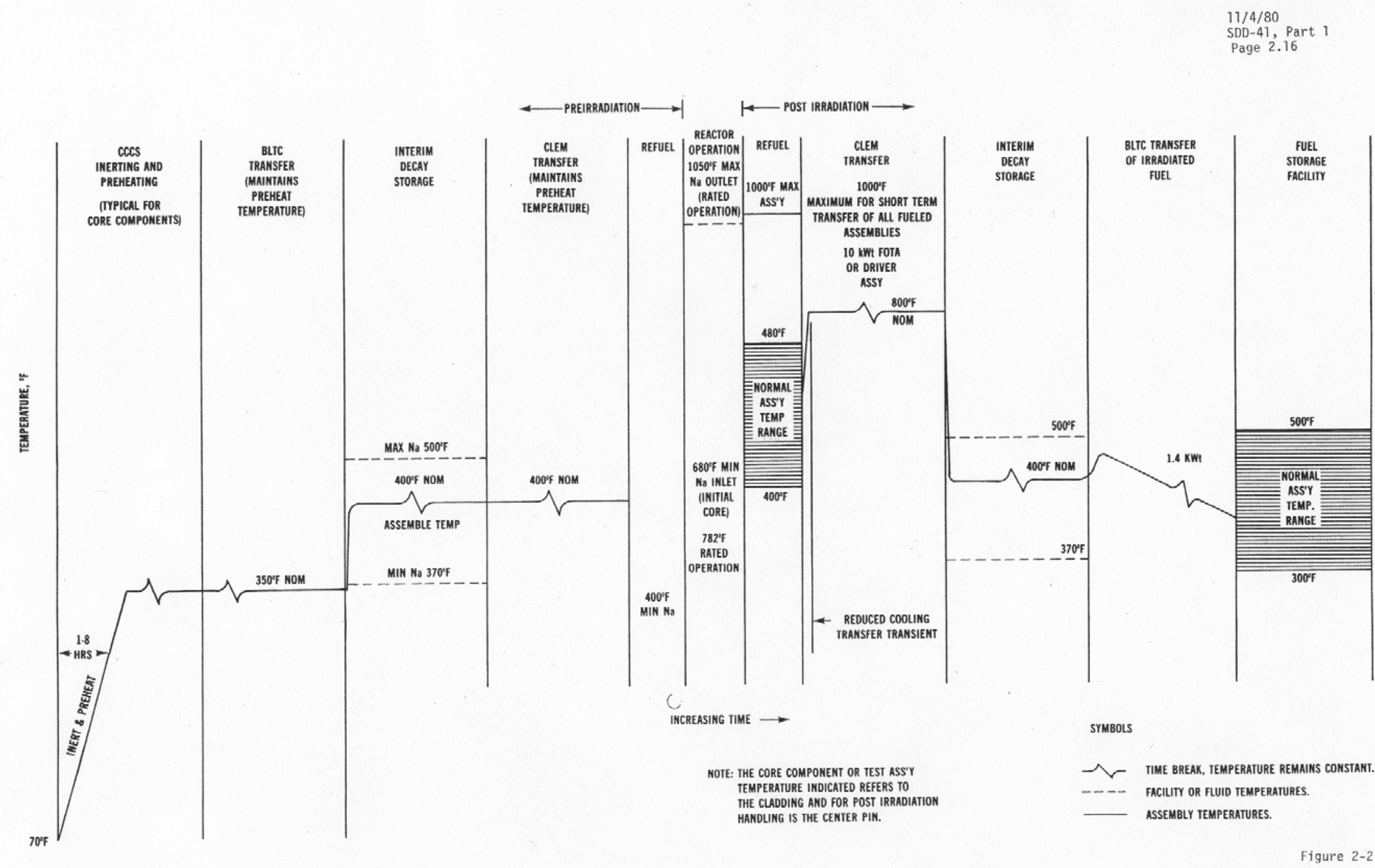

Figure 8. Thermal Profile for FFTF Fuel and Test Assemblies Handling (SDD-41). 
limits, and 3) thermal analyses of fuel element refueling temperatures to determine acceptable margins below the fuel temperature limit.

A simple estimate of coolant, structural, and fuel temperature limits can be made as follows: 1) the acceptable coolant temperature is likely to be in the neighborhood of $50^{\circ} \mathrm{C}\left(100^{\circ} \mathrm{F}\right)$ above the normal melting point, 2) the maximum allowable metal structural temperature (design basis) is likely to be in the neighborhood of the normal maximum operating temperature, perhaps $750^{\circ} \mathrm{C}$ for the advanced alloy used in LS - VHTR, and 3) the maximum allowable fuel temperature is likely to be in the neighborhood of the peak normal operating temperature, perhaps $1200^{\circ} \mathrm{C}$. Based on this simple estimate process, an LS - VHTR fuel handling temperature in the range of $600^{\circ} \mathrm{C}$ to $750^{\circ} \mathrm{C}$ is feasible, assuming that the in-vessel fuel handling machine could be constructed from the same advanced alloy as the reactor vessel.

\subsection{Temperature Rise During Refueling}

To support scoping analysis of LS - VHTR refueling system design, an estimation of the adiabatic temperature rise per unit time in a fuel element during the core refueling has been made. This estimate provides input into determination of in-vessel post-shutdown cool-down times prior to refueling, as well as selection of ex-vessel cooling requirements during fuel element transport from the reactor to the fuel storage facility. A decay heat curve generated for the LSVHTR core was used in the estimation. The curve was obtained by a two-step procedure. In the first step, burnup-dependent cross sections were generated for the LS-VHTR unit fuel element utilizing the WIMS model employed in the LS-VHTR physics studies of FY 2005 [1]. The dimensions for the reference fuel element design (agreed to at the October 2005 coordination meeting) were used in the unit element calculation. In a second step, the time-dependent cross sections were provided to the ORIGEN2 code in order to generate more detailed isotope number densities during the irradiation period; the LS-VHTR fuel burnup is $150 \mathrm{GWd} / \mathrm{t}$. The ORIGEN2 code was also used for generating post-irradiation decay heat data for cooling time intervals from discharge to 50 days post-irradiation. This data was normalized by the initial fuel element power to get a decay heat curve.

The limiting (conservative) temperature rise per unit time was calculated by considering a fuel element that was at decay heat level. It is assumed that for this fuel element, the temperature equilibrates and no heat is removed (adiabatic condition). Then the temperature rise per unit time is calculated from the expression

$$
\frac{\Delta T}{\Delta t}=\frac{q^{\prime \prime \prime}}{\rho c_{p}}
$$

where,
$q^{\prime \prime \prime} \quad$ is the instantaneous power density in the fuel element, i.e., product of the instantaneous normalized decay heat and the initial fuel element power density. 
$\rho c_{p} \quad$ is the product of the effective material density and heat capacity; a value of 2.61 $\mathrm{MW}-\mathrm{s} / \mathrm{K}-\mathrm{m}^{3}$ is assumed in this study.

The reference LS-VHTR design has a hot-condition power density (PD) of $10 \mathrm{MW} / \mathrm{m}^{3}$. For this study, power densities bounding this value have been considered since there would be a distribution in core fuel element power densities at operating conditions. For this reason temperature rise estimates have been made for cases with fuel-element initial power densities of 6.6, 10, and $15 \mathrm{MW} / \mathrm{m}^{3}$. Results are presented in Figure 9 (for the range of 1 day to 50 days).

Temperature rise greater than $500 \mathrm{~K} / \mathrm{hr}$ was observed for immediately after shutdown in the three cases, suggesting that some days of post-irradiation cooling would be required if no cooling path is available (natural, forced, etc.) at various stages of the refueling operation. Obviously, some cooling approaches would be deployed, but, however, these estimates provide a conservative upper bound for the type of temperature rises that would be obtained. Once a definite design is available for the LS-VHTR (including the cooling approaches for the refueling devices), a more detailed calculation of the temperature rise, fuel temperature, and refueling equipment temperature is necessary to confirm that the refueling operation would be performed without overheating of the fuel block and refueling equipment.

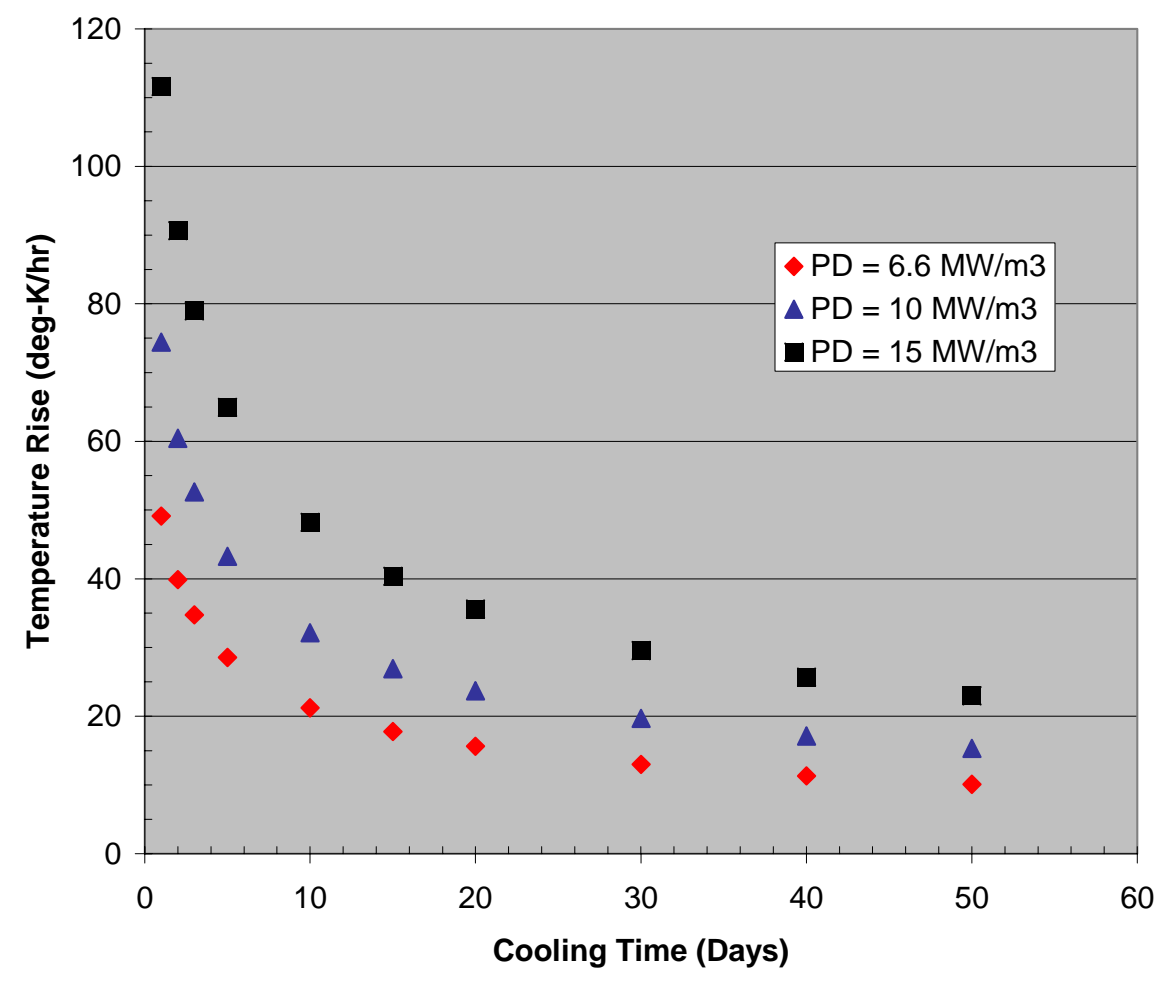

Figure 9. Temperature Rise per Unit Time as a Function of Cooling Time.

\subsection{In-Vessel Fuel Handling Equipment Design and Fuel Restraint Design}

If it is assumed that the in-vessel fuel handling machine can be constructed of the same advanced alloy as the reactor vessel $\left(750^{\circ} \mathrm{C}\right.$ operating temperature $)$, then it is reasonable to expect that the 
LS - VHTR design of the in-vessel fuel handling machine could closely resemble the design proposed for the GT-MHR machine [10]. One possible issue for the LS - VHTR might be the need to provide vertical fuel element restraint, since the density of the coolant salt and the fuel block are comparable. One simple design feature to assure fuel element location might be the installation of a mechanical locking device on the bottom of each fuel block that would engage the fuel handling indent on the next lower fuel block. The grapple portion of the device would closely resemble the grapple on the in-vessel fuel handling machine. Such a device could be engaged and released by mechanical linkages manipulated by simple vertical motions of the invessel handling machine. The device could be constructed of high strength alloy to withstand the high core temperature, but could be relatively light-weight since only modest strength would be needed to overcome the small buoyancy forces. Such a low-mass device would not significantly alter the nuclear or structural performance of the existing LS - VHTR design.

\subsection{Sodium-Cooled Reactor Fuel Handling Design Requirements Relevant to LS-VHTR}

Many of the design requirements for the EBR-II, FFTF, and CRBRP fuel handling systems have relevance to the proposed LS-VHTR design and operating characteristics.

- All in-vessel fuel handling operations are conducted remotely, most while submerged under opaque liquid sodium at high temperature (EBR-II $700^{\circ} \mathrm{F} / 371^{\circ} \mathrm{C}$; FFTF $480^{\circ} \mathrm{F} / 249^{\circ} \mathrm{C}$ nominal, $1000^{\circ} \mathrm{F} / 538^{\circ} \mathrm{C}$ maximum).

- Fuel handling mechanisms are designed to operate for extended periods under sodium or in sodium-argon environments with very high reliability. The mechanisms are repairable and replaceable, and have a low failure rate and a long time between failures. Mechanisms are constructed from materials (mostly stainless steel) that are appropriate for the mission requirements.

- Fuel handling mechanisms are designed for precise alignment that can be maintained for prolonged operations times, since remote re-alignment while submerged is difficult.

- Positioning of grippers is performed with automated computer control; components are designed with guides (funnels, slides, ports) to facilitate mating and gripping operations.

- To the extent possible, sensing mechanisms are employed to verify all positioning, grasping, movement, transfer, and release functions. Such mechanisms include instrumentation on rotating and elevating machinery, as well as manual "feel" through mechanical links.

- Fuel handling and transfer equipment is designed to handle one subassembly at a time. Individual fuel subassembly weights are in the range of approximately $100 \mathrm{lbs}$ for EBR-II to about $450 \mathrm{lbs}$ for CRBRP.

- Grasping and gripping mechanisms are designed to minimize the potential for dropping a subassembly.

- Transfer operations are accomplished with positive, mechanically-actuated displacement actions (without reliance on gravity).

- In-vessel fuel handling mechanisms are designed to have drive mechanisms with vertical and rotary motion. 
- For EBR-II, shaft penetrations through the primary tank cover are equipped with packing gland seals to minimize escape of argon cover gas and prevent air in-leakage. For FFTF and CRBRP, vessel head ports are mated to special removable valves to control leakage.

- Where possible, fuel handling mechanisms are designed with additional capability to accommodate non-standard operations with bent, damaged, or incorrectly positioned subassemblies.

- The overall system configuration is selected on the basis of time-motion studies and the refueling interval requirement, to minimize reactor shutdown time. 


\section{$\underline{\text { References }}$}

1. D. T. Ingersoll, et al., "Status of Physics and Safety Analyses for the Liquid-Salt-Cooled Very High-Temperature Reactor (LS-VHTR), ORNL/TM-2005/218, September, 2005.

2. EBR-II System Design Descriptions, Volume II, Chapter 5, Fuel Handling System, Argonne National Laboratory, June 15, 1971.

3. Leonard J. Koch, Experimental Breeder Reactor-II (EBR-II), An Integrated Experimental Fast Reactor Power Station.

4. C. P. Cabell, "A Summary Description of the Fast Flux Test Facility," HEDL-400, December, 1980.

5. Fast Flux Test Facility System Design Description No. 41 Part 1, Reactor Refueling System, Rev. 11, April 6, 1983.

6. Clinch River Breeder Reactor Plant System Design Description, Reactor Refueling System, SDD-41, Revision 27, July, 1983.

7. Clinch River Breeder Reactor Plant Reference Design Report, Vol. 1, June, 1974.

8. Clinch River Breeder Reactor Project, 1974 Technical Progress Report.

9. T. K. Kim, T. A. Taiwo, and W. S. Yang, "Preliminary Neutronic Studies for the LiquidSalt-Cooled Very High Temperature Reactor (LS-VHTR),” ANL-GenIV-052, Argonne National Laboratory, August 31, 2005.

10. "Gas Turbine-Modular Helium Reactor (GT-MHR) Conceptual Design Description Report,” General Atomics Report 910720, Revision 1, July, 1996. 


\section{Appendix A}

\section{FFTF Fuel Handling System: Summary Description}

The design and performance characteristics of the FFTF fuel handling system have been reviewed for relevance to the proposed Liquid Salt-Very High Temperature Reactor (LS-VHTR). This summary provides a brief description of the FFTF fuel handling system and its operation.

\section{FFTF Fuel Handling System (Ref. 4)}

The FFTF Reactor Refueling System includes facilities for the receipt, conditioning, storage, installation in and removal from the core of all core components (driver fuel assemblies, control assemblies) and test assemblies that are routinely removable. Limited examination and packaging capabilities are also provided. All the principal equipment incorporates an inert argon gas environment for the fuel and test assemblies. The Reactor Refueling System includes components both inside and outside the reactor.

The design of the FFTF fuel handling system is described in Ref. 4, and the system design requirements are given in Ref. 5. These documents are the sources for information contained in this summary description, which focuses on fuel assembly handling design concepts, equipment, and procedures.

\section{$\underline{\text { Ex-Reactor Components }}$}

An overall plan view of the FFTF reactor refueling facilities is shown in Figure A1.

The principal ex-reactor component is the Closed Loop Ex-Vessel Machine (CLEM) shown in Figure A2. The CLEM loads all components into the reactor and removes all components from the reactor.

Other principal ex-reactor components include two Core Component Conditioning Stations, a Test Assembly Conditioning Station, a Bottom Loading Transfer Cask, an Interim Decay Storage (IDS) Vessel, an Interim Examination and Maintenance (IEM) Cell, a Fuel Storage Facility and a Cask Loadout Station.

The Reactor Refueling System also employs the three Fuel Transfer Ports, eight test position spoolpieces, two floor valve adapters and the Test Transfer Port, and the Reactor Containment Building Cranes.

\section{$\underline{\text { In-Reactor Components }}$}

The in-reactor components consist of three In-Vessel Handling Machines plus the three In-Vessel Storage Modules. 


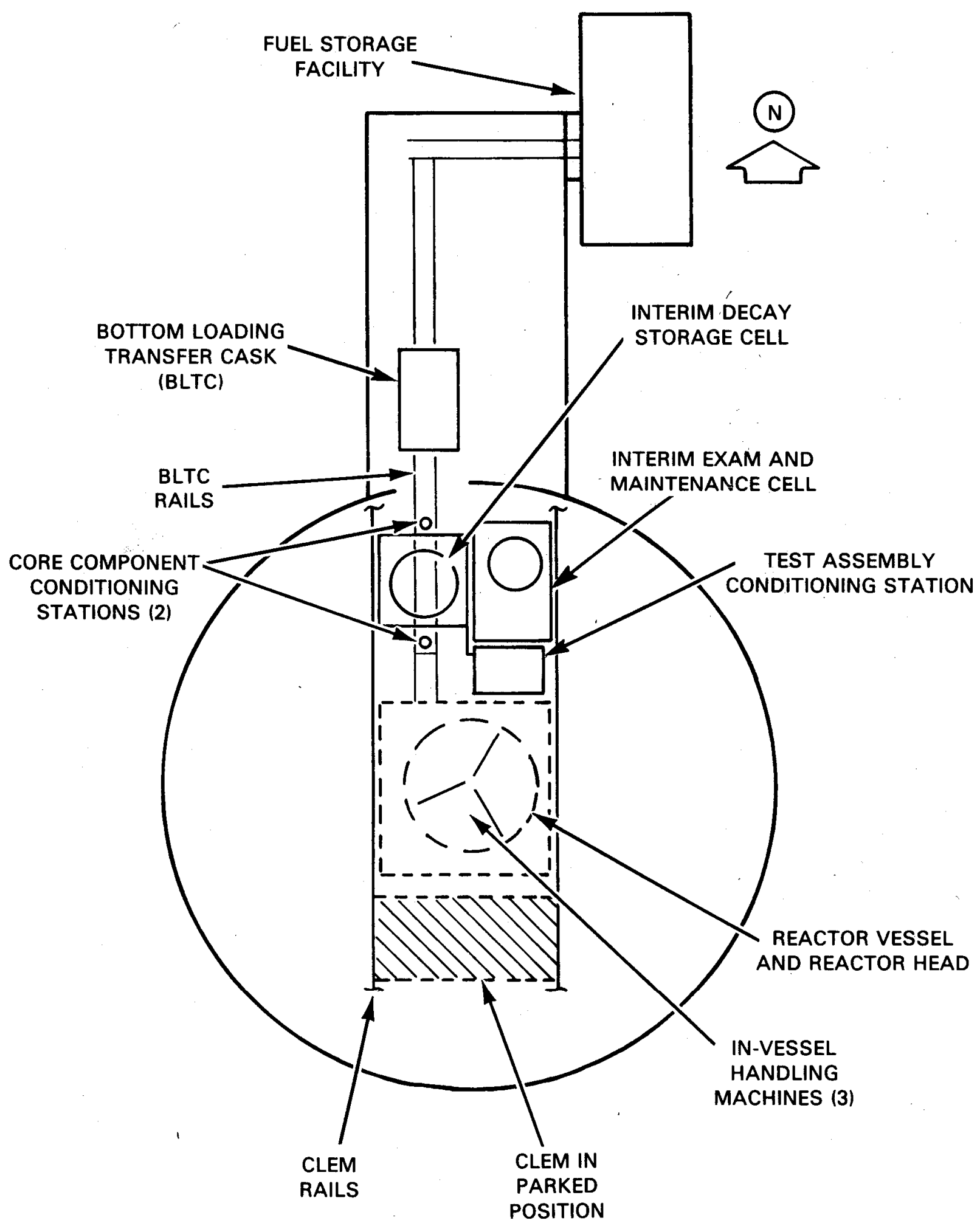

Figure A1. General Arrangement of Reactor Refueling Facilities. 


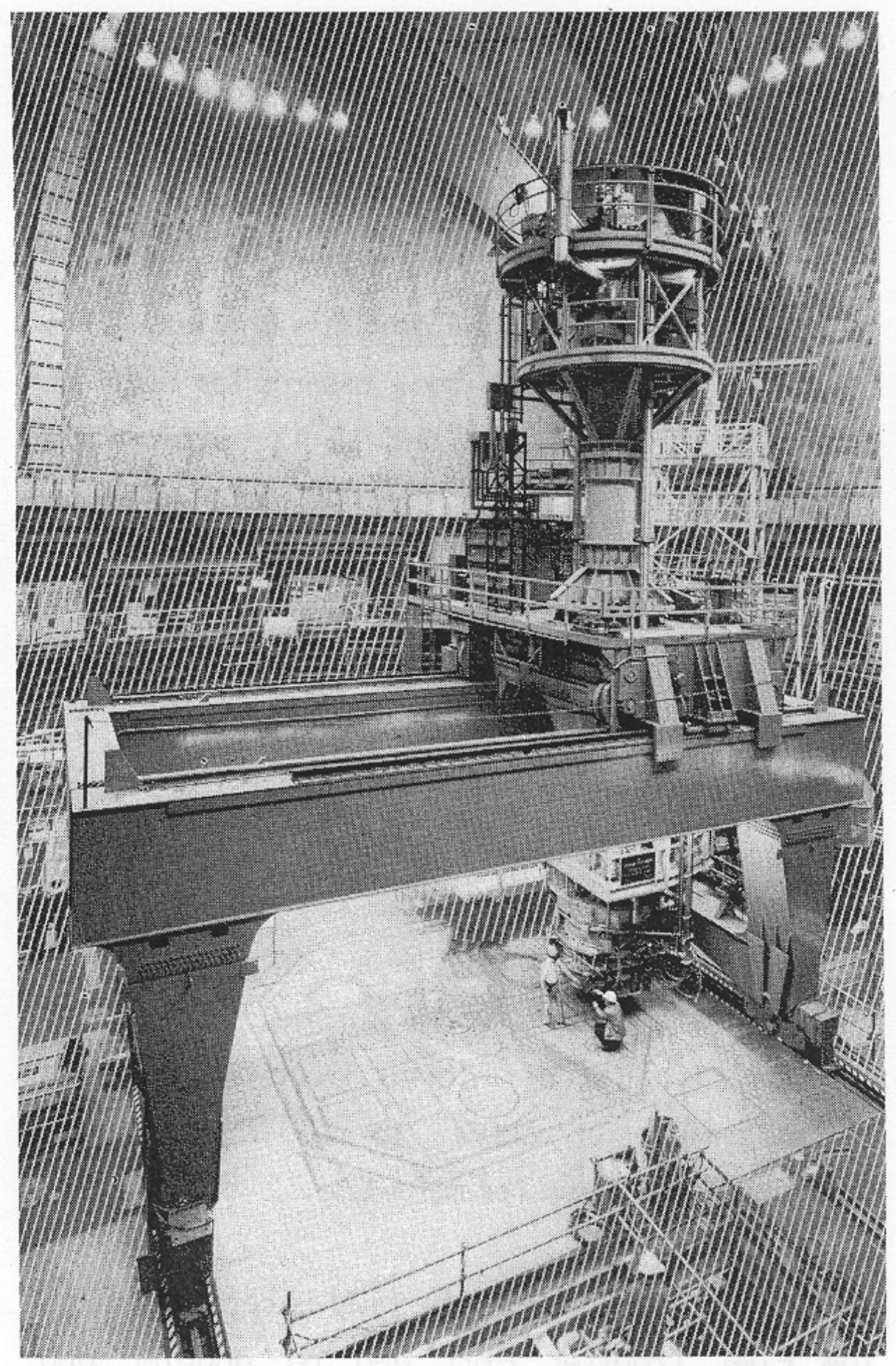

Figure A2. Closed Loop Ex-Vessel Machine (CLEM). 


\section{System Functions}

The Reactor Refueling System handles three types of core assemblies: 12-ft assemblies such as Driver Fuel; 40-ft assemblies such as Fuels Open Test Assemblies (FOTA), which are loaded into the reactor full-length but are cut into two sections before removal; and 40$\mathrm{ft}$ assemblies such as Materials Open Test Assemblies (MOTA), which are loaded into and removed from the reactor as full-length sections. The typical sequence for driver fuel handling operation is summarized below, along with a brief description of contamination control and inventory control practices.

\section{Handling of 12-Foot Assemblies}

In the handling of twelve-foot assemblies such as driver fuel (Figures A3 and A4), an incoming assembly is first lowered by the crane into one of the two Core Component Conditioning Stations. In this station, the assembly is flooded with argon and heated to approximately $450^{\circ} \mathrm{F}\left(232^{\circ} \mathrm{C}\right)$. The assembly is then picked up by the Bottom Loading Transfer Cask and is transported, in an argon atmosphere, to the Interim Decay Storage Vessel. The assembly is then lowered into a sodium-filled Core Component Pot in the Interim Decay Storage Vessel. The assembly is held in Interim Decay Storage in liquid sodium at $500^{\circ} \mathrm{F}$ $\left(260^{\circ} \mathrm{C}\right)$ to $600^{\circ} \mathrm{F}\left(316^{\circ} \mathrm{C}\right)$ until the reactor is shut down for refueling.

At the reactor, the plug is removed from the Fuel Transfer Port and an adapter and floor valve are installed on the port. The control rod drive shafts are also disconnected, and the Instrument Trees are moved to their stored positions.

The CLEM then picks up the Core Component Pot containing the assembly and lowers it into an in-vessel storage module through the Fuel Transfer Port.

The next objective in the handling sequence is placing the assembly into the reactor core. First, the In-Vessel Handling Machine (IVHM) removes a spent assembly from the core and places it into an in-vessel storage module position. The IVHM then removes the new assembly from the Core Component Pot and places the new assembly into the core. Finally, the IVHM removes a spent assembly from the in-vessel storage module and places it into the Core Component Pot.

The CLEM then picks up the Core Component Pot and its contained spent assembly and places the Core Component Pot into the Interim Decay Storage Vessel. After a suitable decay period, the Bottom Loading Transfer Cask picks up the spent assembly and transfers it out of containment to the Fuel Storage Facility.

Before reactor startup, the In-Vessel Handling Machines are placed in their "stored" positions in the reactor. The Instrument Trees and Control Rod Shafts are restored to poweroperation status, the adapter and floor valve are removed and the Fuel Transfer Port is sealed with its plug. 


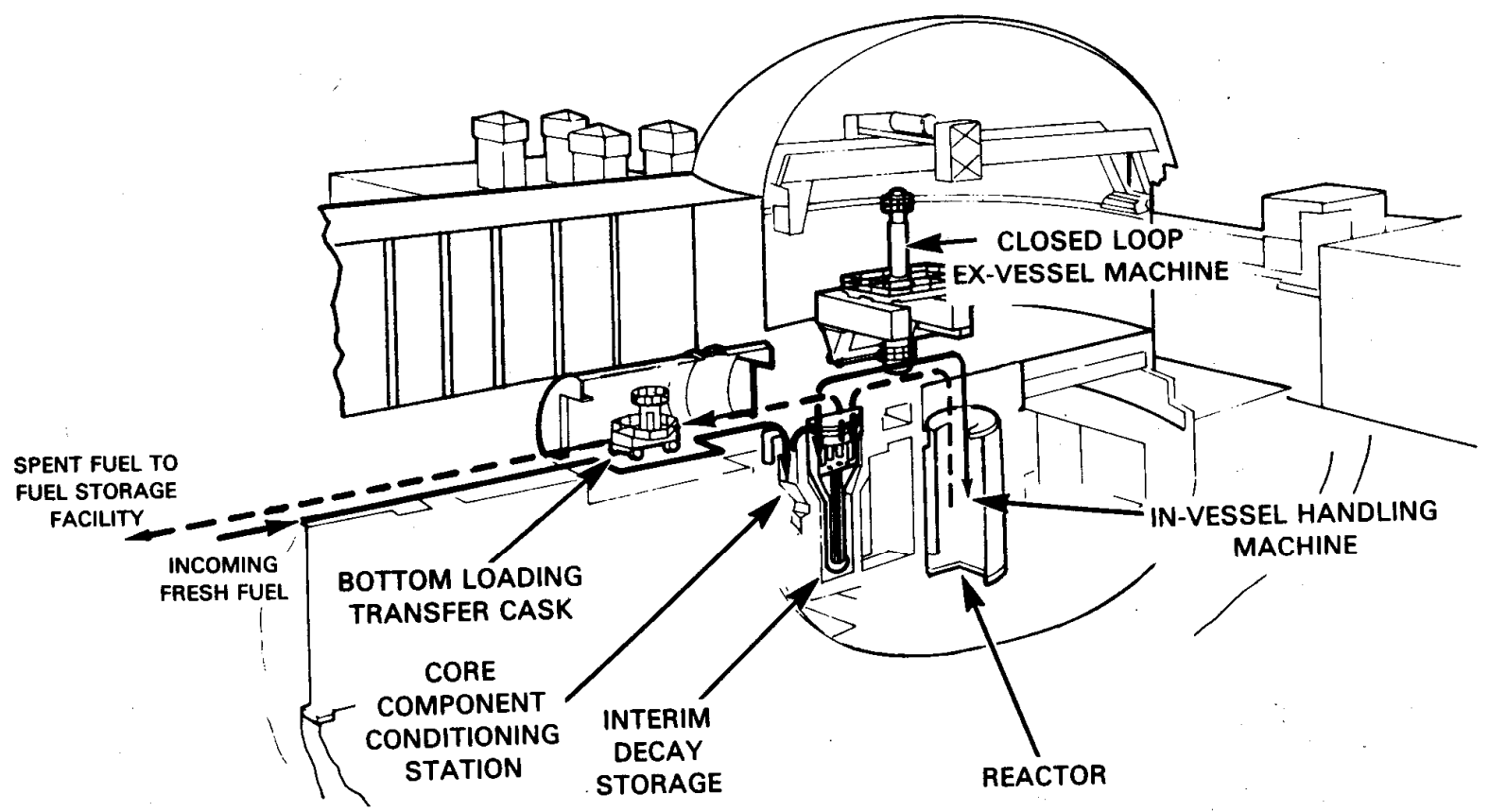

Figure A3. Driver Fuel Handling Séquence.

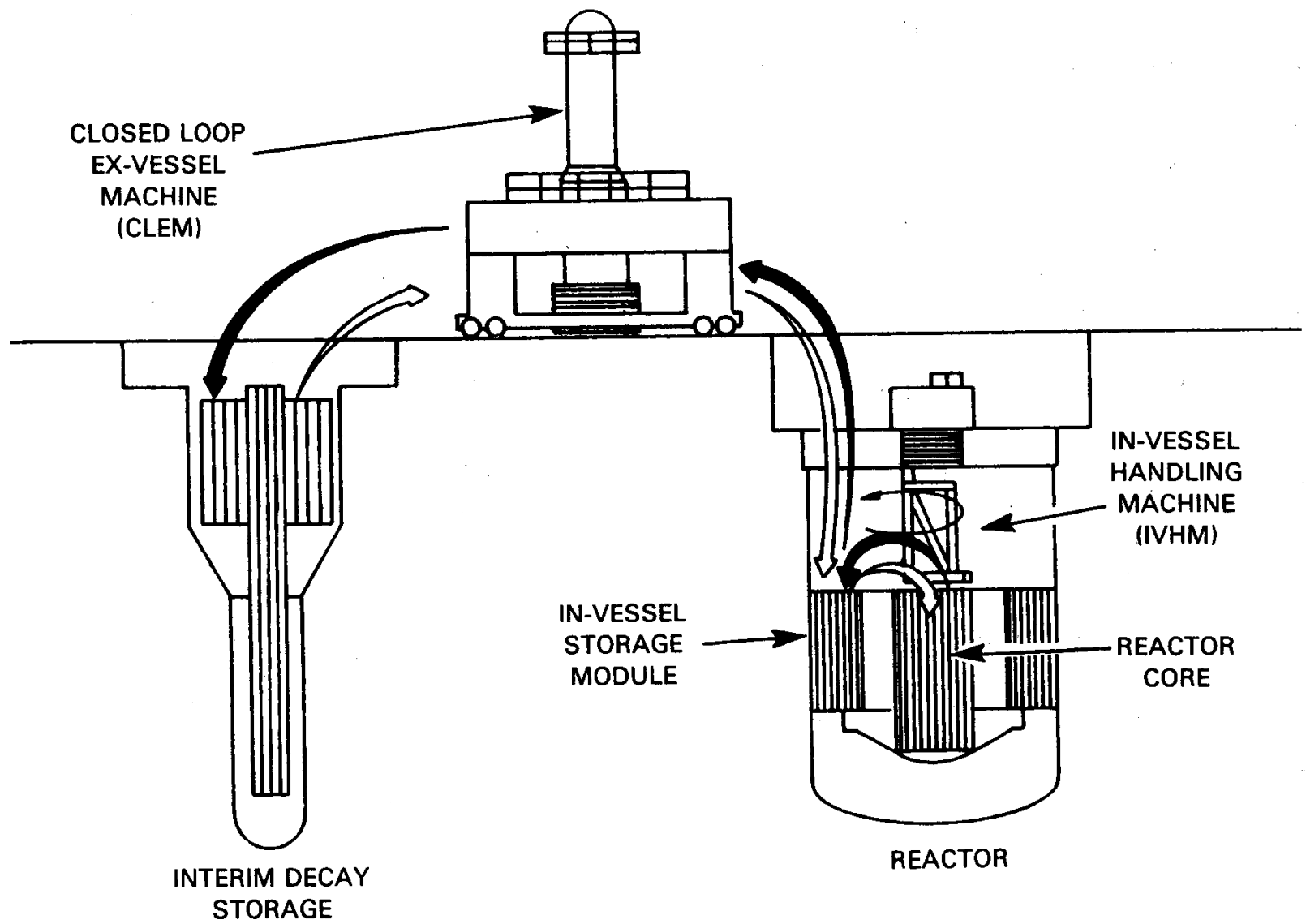

Figure A4. Driver Fuel Handling Sequence Between Interim Decay Storage and Reactor Vessel. 


\section{$\underline{\text { Use of Floor Valves and Adapters }}$}

The confinement of fission gases and contaminants is of special importance in all areas of fuel handling. Access to all the inerted or potentially contaminated facilities requires the use of equipment such as floor valves (Figure A5) and adapters unique to the particular facility or port involved. The most important adapters are the two Floor Valve Adapters and the Test Transfer Port.

\section{$\underline{\text { Inventory Control }}$}

Because of the quantity of assemblies, the many possible variations in assembly types and the lack of direct observation at most residence or transfer points, an inventory system is provided. The control system traces all core assemblies, core component pots, etc. by location and also records the status of all storage locations.

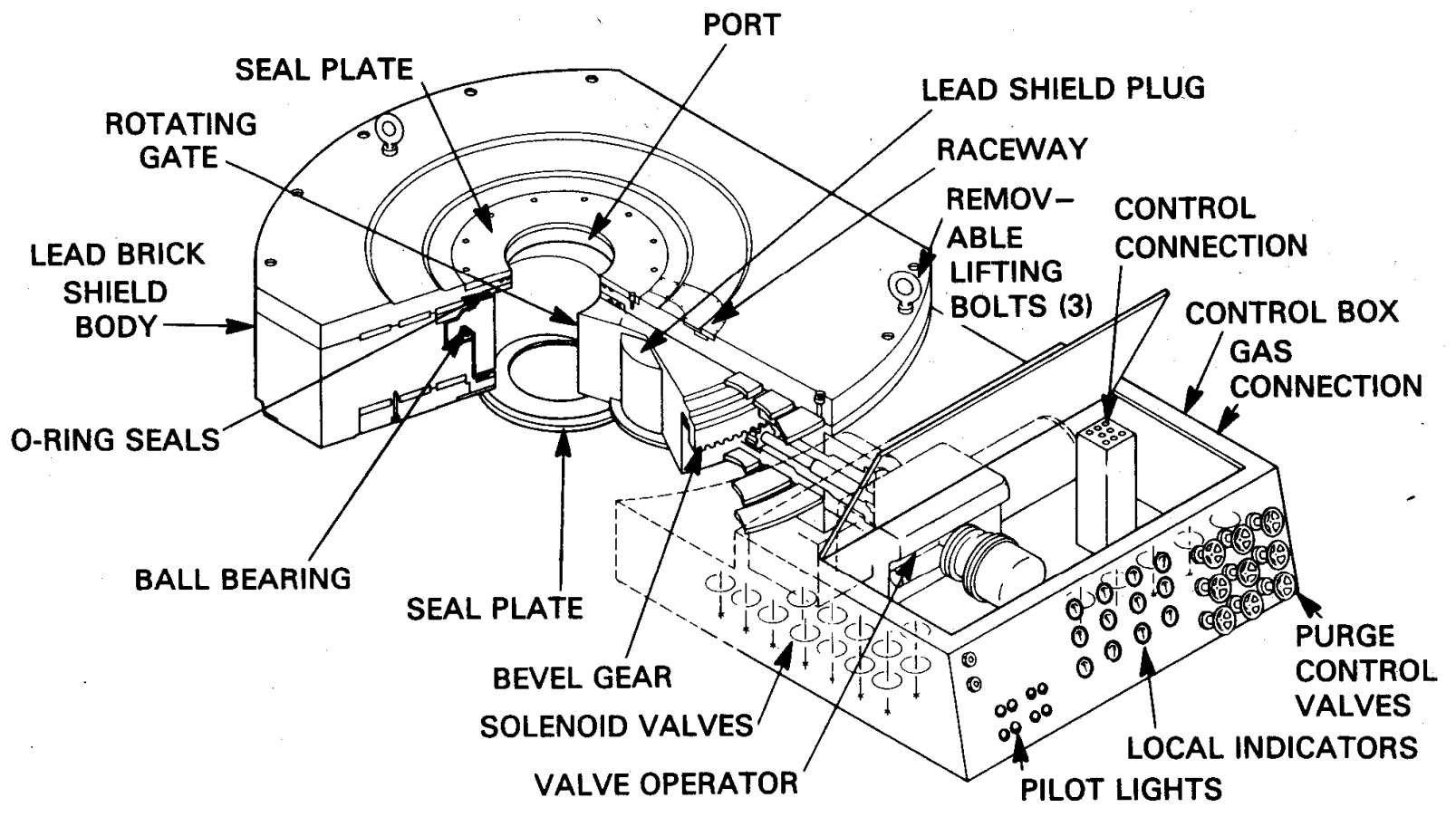

Figure A5. Floor Valve. 


\section{$\underline{\text { System Components }}$}

\section{Closed Loop Ex-Vessel Machine}

The function of the Closed Loop Ex-Vessel Machine (CLEM) is to transfer reactor core components and test assemblies (which may be up to $40 \mathrm{ft}$ long) between the various FFTF refueling stations. The CLEM has a $10-\mathrm{kWt}$ heat removal capability and handles one component at a time.

The CLEM is $61 \mathrm{ft}$ high and weighs 217 tons (Figure A6). It moves on a 40-ft wide transporter on tracks in the operating deck.

The temperature of the CLEM is controlled by a cold-wall cooling system and an electrical heating system. The cold-wall cooling system consists of an 8-in. pipe, having an array of straight fins attached to the outside. The normal cooling mode for the CLEM is by internal radiation of fuel assembly decay heat to the cold wall, which is externally cooled by ambient air circulated over the fins. During normal core component handling operations, the fuel pin cladding temperature of the driver fuel is limited to $1000^{\circ} \mathrm{F}\left(538^{\circ} \mathrm{C}\right)$.

The CLEM operator controls all machine operations from the control console in the cab mounted on the transporter trolley. The control of CLEM is semiautomatic, i.e., operations are performed automatically after the operator initiates a command. Interlocks to control the machine's operations have been incorporated into the design to meet safety requirements.

Manual overrides are also provided to permit the operator to take control if necessary. The grapple speed and push-pull load requirements in handling fuel are controlled through all modes of operation. Indexing of the CLEM to a refueling station is accomplished by manually operated controls.

The CLEM is hermetically sealed to a refueling station by lowering the movable closure valve which mates with a floor valve. Sealing this interface is accomplished by two inflatable seals (providing a double barrier), which engage the floor valve. The air trapped between the movable closure valve and floor valve is purged by the plant argon supply and vent system through hose connections made after the CLEM is indexed to a Fuel Transfer Port or Test Transfer Port.

Electrical and instrumentation connections are also made at each refueling station to control and monitor the operation of the floor valve and provide the interlock connections to assure safe operation, e.g., CLEM and the In-Vessel Handling Machine (IVHM) are interlocked at the reactor to prevent simultaneous operation in their common operating space.

The major subassemblies of the CLEM include: the grapple drive system, cask body modules, service platforms, a movable closure valve that mates with the floor valve, the cold-wall assembly, and a seal monitoring system. 


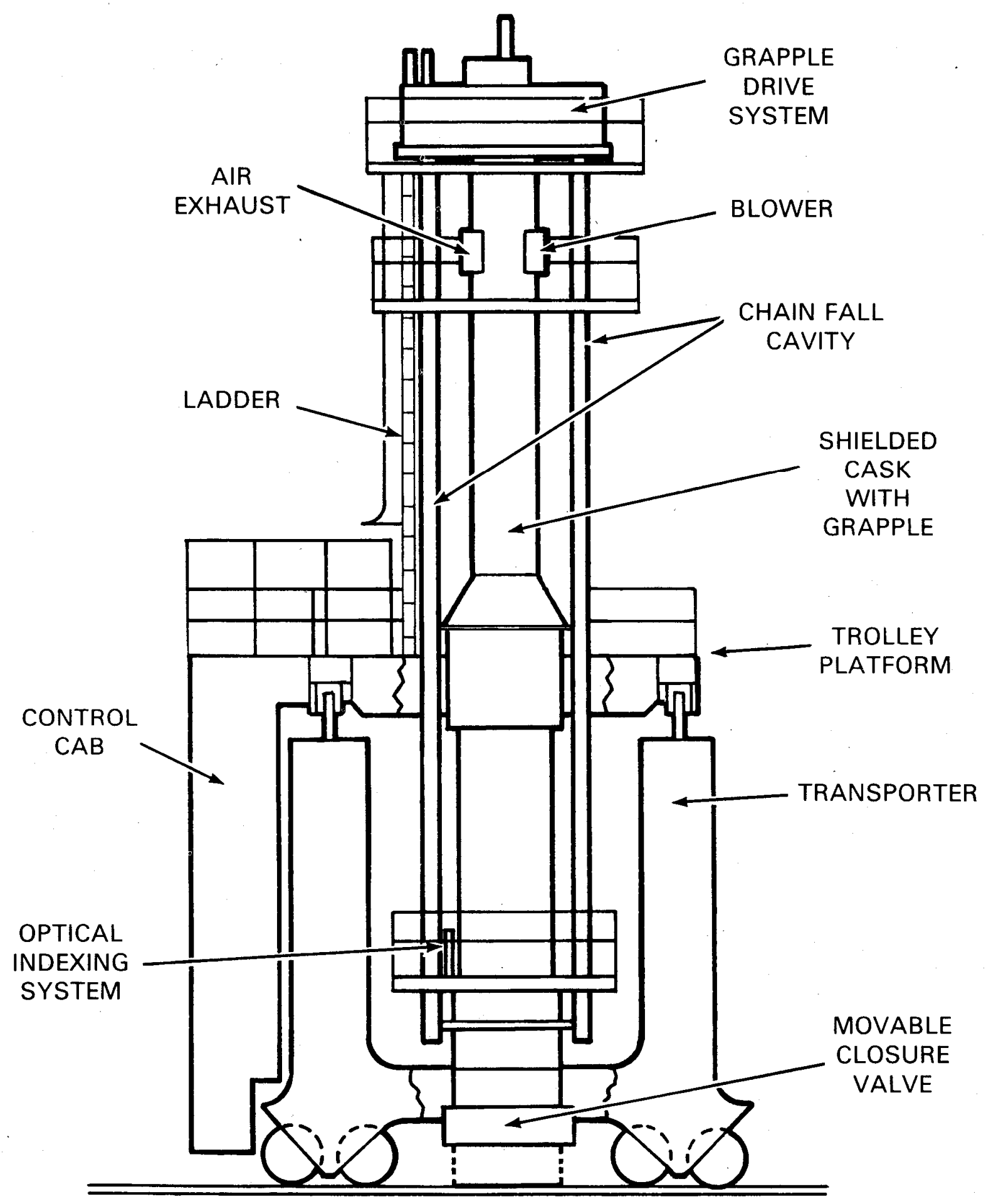

Figure A6. Schematic of Closed Loop Ex-Vessel Machine (CLEM) and Transporter. 


\section{Bottom Loading Transfer Cask}

The Bottom Loading Transfer Cask (BLTC) (Figure A7) transfers core components up to $13.5 \mathrm{ft}$ long between transfer stations inside and outside the FFTF Containment Building. The BLTC is a single-barrel, internally cooled machine that travels on rails through the equipment airlock and in line with the Core Component Conditioning Stations and Interim Decay Storage. The BLTC grapple reaches through a floor valve on the operating floor and into each transfer station or cell to install or remove a core component for transfer to another station. The BLTC is about $10 \mathrm{ft}$ wide by $22 \mathrm{ft}$ long by $19 \mathrm{ft}$ high. It is made up of three main parts: the cask, the dolly and the control system. The total weight is 72.5 tons.

The cask provides the shielding, inert environment, confinement, component grappling and 1.4$\mathrm{kWt}$ cooling capability required to handle sodium-wetted, irradiated core components. It is about 8 in. inside diameter. The dolly provides traverse drive, cask elevation and seismic restraint functions. The control system provides the control consoles, motor control equipment and all interconnecting cable. Control of the BLTC is semiautomatic; key operations are automatically performed after the operator initiates a command. Interlocks are incorporated to meet safety requirements. Status lights indicate the exact machine conditions during all operations. Manual overrides permit the operator to complete key operations in case of a control system failure.

The BLTC's normal cooling mode is by forced argon gas circulated through a closed system. The circulating gas transfers heat from the core component to the cask shielding wall.

\section{Core Component Conditioning Stations}

The function of the two Core Component Conditioning Stations (Figure A8) is to prepare 12-ft long core components for operation in liquid sodium at elevated temperatures. The components are immersed in an argon atmosphere and heated to $450^{\circ} \mathrm{F}\left(232^{\circ} \mathrm{C}\right)$.

Cooling nitrogen is supplied to the exterior of the separate cells, up through the vaults, to maintain $100^{\circ} \mathrm{F}\left(38^{\circ} \mathrm{C}\right)$ average cell wall temperature throughout the station.

Each station contains a heater-getter cell for heating the argon and an inerting and preheating cell. One station also contains a transfer cell that permits transfer of up to $13.5-\mathrm{ft}$ long components between the Closed Loop Ex-Vessel Machine (CLEM) and the Bottom Loading Transfer Cask (BLTC).

\section{$\underline{\text { Test Assembly Conditioning Station }}$}

The Test Assembly Conditioning Station (TACS) provides argon flooding and preheating to $450^{\circ} \mathrm{F}\left(232^{\circ} \mathrm{C}\right)$ for 2740 - $\mathrm{ft}$ long test assemblies. Space is also provided for storage of radioactive test assemblies, recycled closed loop in-reactor assemblies and shield plugs. All storage spaces will accommodate 40 -ft assemblies. Design is generally similar to that of the Core Component Conditioning Stations. (See Figure A1 for location). 


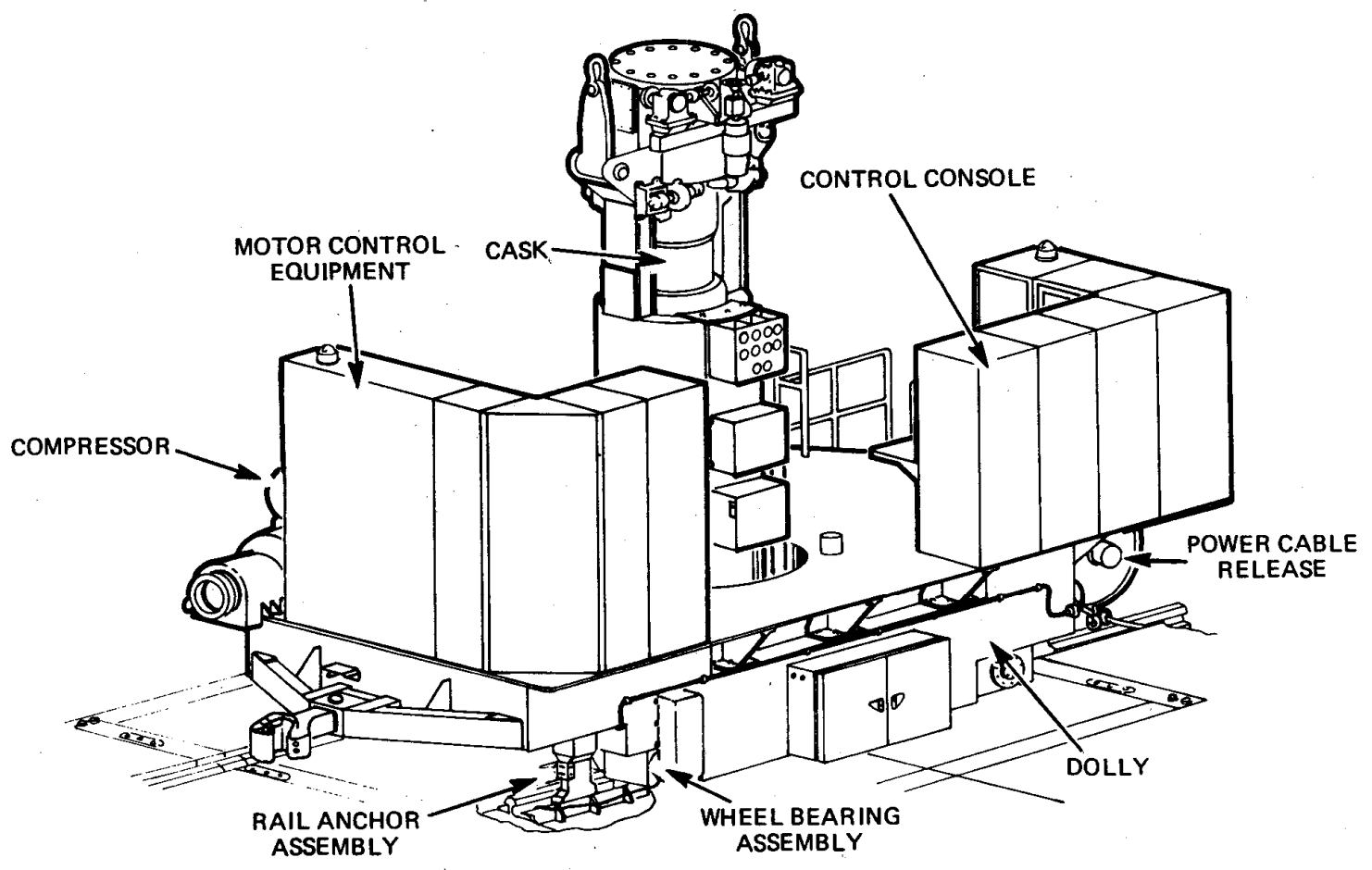

Figure A7. Bottom Loading Transfer Cask Schematic.

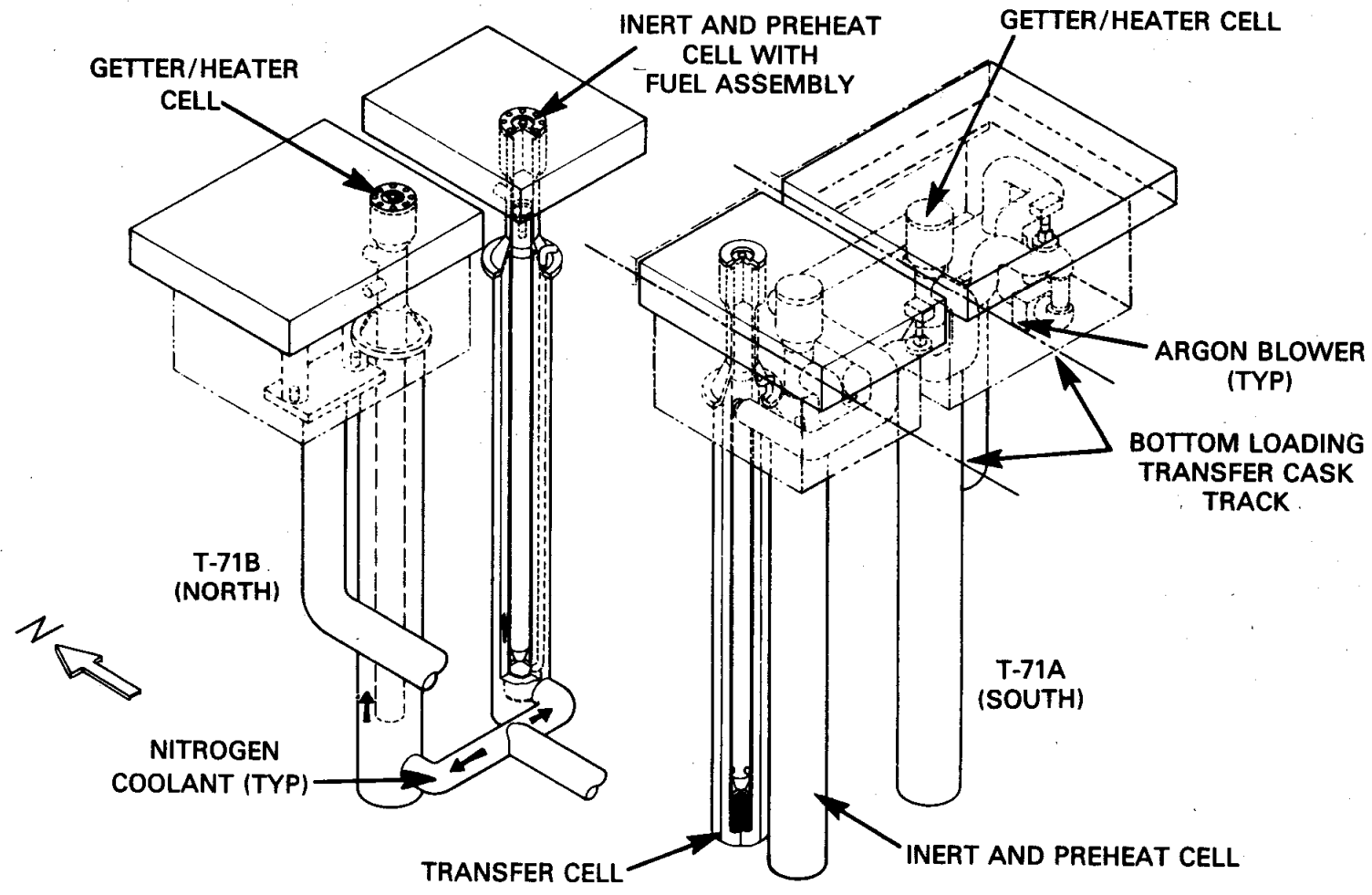

Figure A8. Core Component Conditioning Stations. 


\section{Interim Decay Storage}

The primary function of the Interim Decay Storage (IDS) (Figure A9) is to provide a passive, controlled liquid sodium environment for damage-free temporary storage for new components en route to the reactor and for irradiated core components and test assemblies removed from the reactor. Sodium temperature is held between $500^{\circ} \mathrm{F}\left(260^{\circ} \mathrm{C}\right)$ and $600^{\circ} \mathrm{F}\left(316^{\circ} \mathrm{C}\right)$. The IDS facility is located between the Closed Loop Ex-Vessel Machine (CLEM) rails, in a rectangular steel-lined shielded concrete cell lying entirely below the operating floor, with the top flush with the operating floor. The Bottom Loading Transfer Cask (BLTC) rails traverse the IDS cover. The IDS consists of a rotatable storage basket submerged in liquid sodium in a stainless steel tank surrounded by a guard vessel.

Storage positions are provided for 112 core components 12 feet long in the upper section of the IDS storage basket. Ten storage tubes are included near the center of the basket to store the 40 $\mathrm{ft}$ test assemblies such as the FOTAs.

During normal operation, two independent cooling systems are available. The IDS Sodium Cooling System circulates sodium from the IDS to an intermediate sodium $\mathrm{NaK}$ heat exchanger. The $\mathrm{NaK}$ is in turn cooled by a mobiltherm cooler.

If it is necessary to remove the primary sodium cooling system from service for any reason, a backup nitrogen gas cooling system and an emergency natural convection air cooling system may be utilized.

\section{Fuel Storage Facility}

The Fuel Storage Facility (FSF, Figure A10) was designed as a separate project after the FFTF design was completed. The project includes a main 12,200 $\mathrm{ft}^{2}$ Fuel Storage Facility building and a $72 \mathrm{ft}$ by $72 \mathrm{ft}$ extension of the Reactor Service Building (RSB). It is designed to handle fuel for the first five years of FFTF operation. The fuel storage vessel, $21 \mathrm{ft}$ in diameter and $24 \mathrm{ft}$ deep, contains liquid sodium for cooling spent fuel from the FFTF. It is surrounded by a guard tank. Two heat exchanger systems dissipate decay heat from the irradiated fuel elements immersed in the sodium far storage.

The $62 \mathrm{ft}$ high RSB extension provides an enclosure for movement of fuel between the FFTF and FSF. The building extension also contains a cask loadout station below ground, where spent fuel elements can be placed in casks for offsite shipment. 


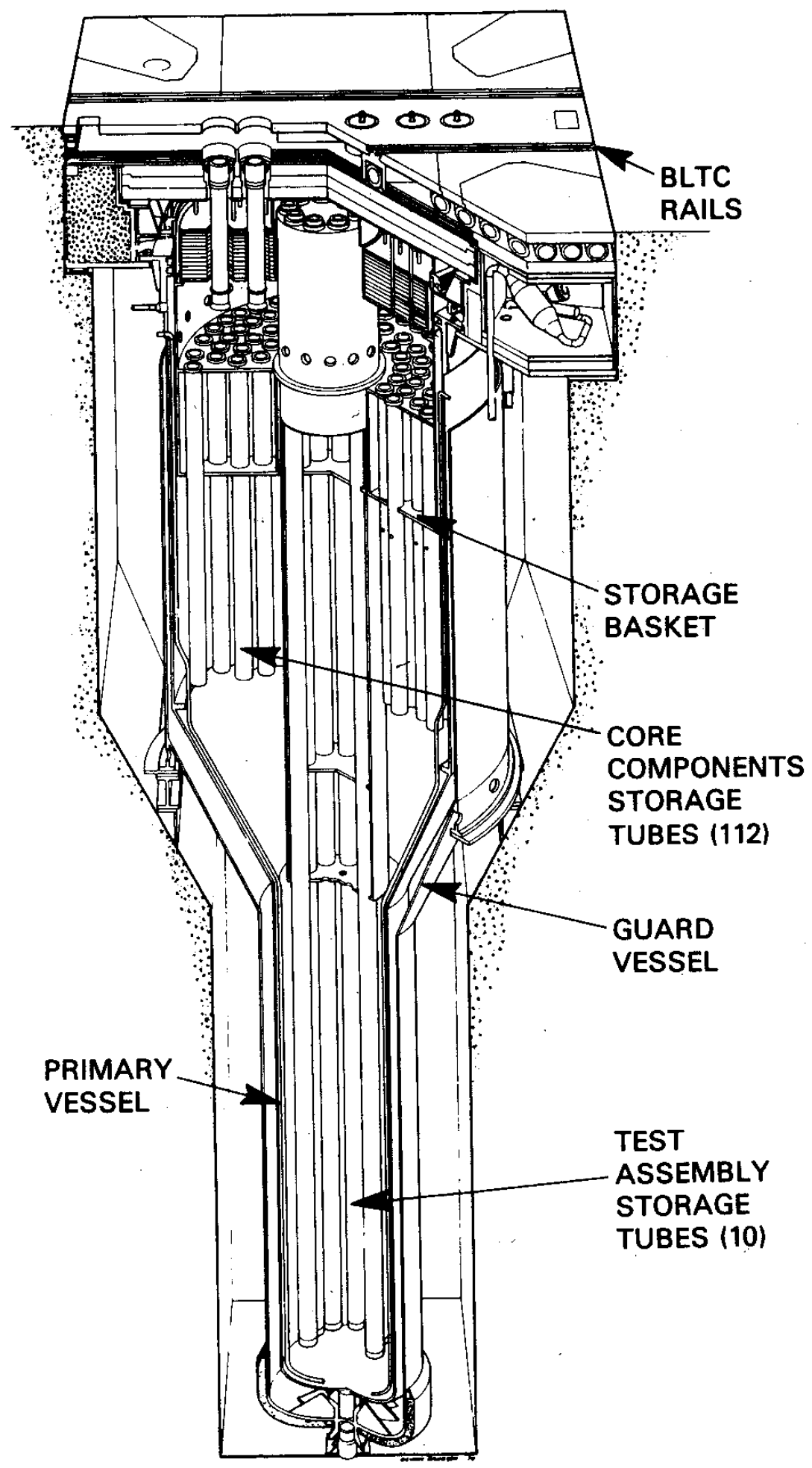

Figure A9. Interim Decay Storage. 


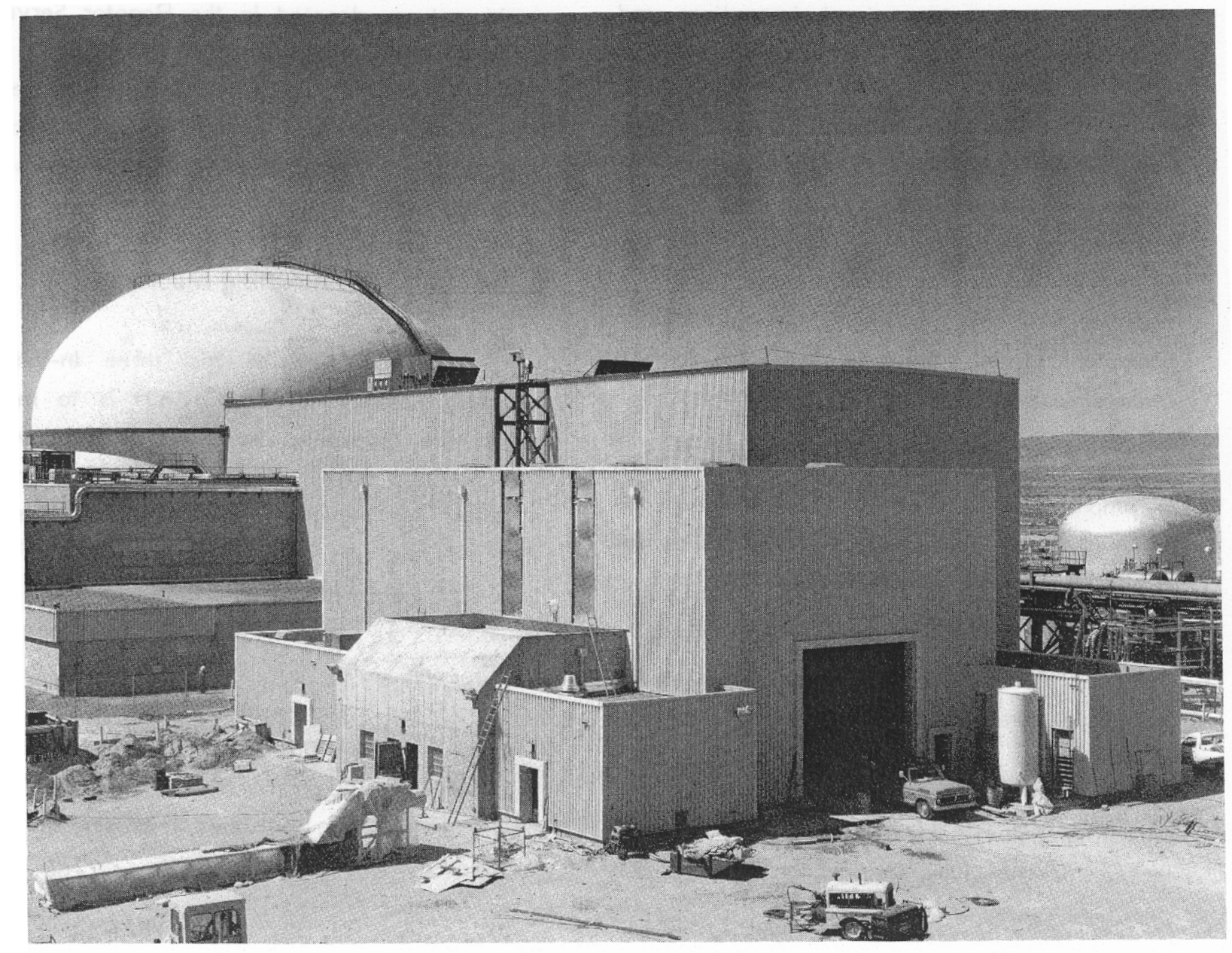

Figure A10. Fuel Storage Facility (under construction).

\section{$\underline{\text { Interim Examination and Maintenance Cell }}$}

The Interim Examination and Maintenance (IEM) Cell is a shielded hot-cell complex that provides a reliable means of conducting nondestructive examinations of test assemblies and core components under controlled argon atmosphere conditions. (See Figure A1 for location).

The IEM Cell contains equipment necessary for disassembly, reassembly and requalification of test assemblies and components. Nondestructive examinations that can be performed include dimensional checks, weighing, gamma scanning, visual inspections and photography.

The IEM Cell can also be used to perform limited maintenance of plant equipment, or to prepare plant equipment for transfer to other maintenance facilities. Cell ceiling valves and an access plug are provided over the cell for transfer of all core components and maintenance equipment in and out of the IEM Cell. Sodium removal facilities are included in the cell. 


\section{$\underline{\text { In-Vessel Handling Machines }}$}

The function of the three In-Vessel Handling Machines (Figure A11) is to move 12-ft core assemblies back and forth between the reactor core and the In-Vessel Storage Modules, and between the storage locations in the modules and the Core Component Pots located beneath the Fuel Transfer Ports. All movements are under sodium.

These movements supplement the functions of the CLEM, which operates through the three Fuel Transfer Ports to place Core Component Pots into the In-Vessel Storage Modules and to remove the pots.

Each of the three IVHMs services its own 120-degree sector of the reactor core. Figure A12 is a plan view showing the locations of the In-Vessel Handling Machines and the In-Vessel Storage Modules. Figure A13 is an elevation view showing one of the In-Vessel Handling Machines in its position in the reactor.

Each IVHM includes a large plug (known as the Reactor Refueling Plug) installed in the reactor head. Eccentrically mounted on the plug, inside the vessel, is an arm structure. Attached to this structure is a grappling device used to grasp core components. Both the plug and arm structure can be rotated by independent ex-vessel drive systems and the arm structure can be raised or lowered.

The coordinated movement of the plug and arm structure allows operators to place the grappling device over any core or storage location within the IVHM's trisector.

The control console employs a computer programmed by a tape containing the sequence of moves for each component being handled.

The core component identification technique is based on use of notches on the outside of the core component handling socket; these notches are positioned geometrically to represent the serial number in binary count.

During reactor operation, the IVHM arm is stored radially adjacent to the core, near the vessel wall.

\section{$\underline{\text { Shield Plug Handling and Storage }}$}

A Plug Handling Fixture removes, transports and replaces the FFTF shield plugs. The Plug Handling Fixture is a portable machine with a winch assembly and grapple enclosed in an airtight container. It is moved by the cranes in the FFTF Containment Building and is normally stored in the Containment Building over the Shield Plug Storage Station. The Plug Handling Fixture is nominally $6 \mathrm{ft}$ in diameter, $13 \mathrm{ft}$ high, and weighs 17 tons. The control mode is manual with automatic override shutoff at safety or operational setpoints. The shield plug storage station vault is located west of the reactor, just south of primary sodium pump No. 3. The argon-filled section of the vault contains storage positions for various types of shield plugs. Air cells are provided for general purpose storage. 


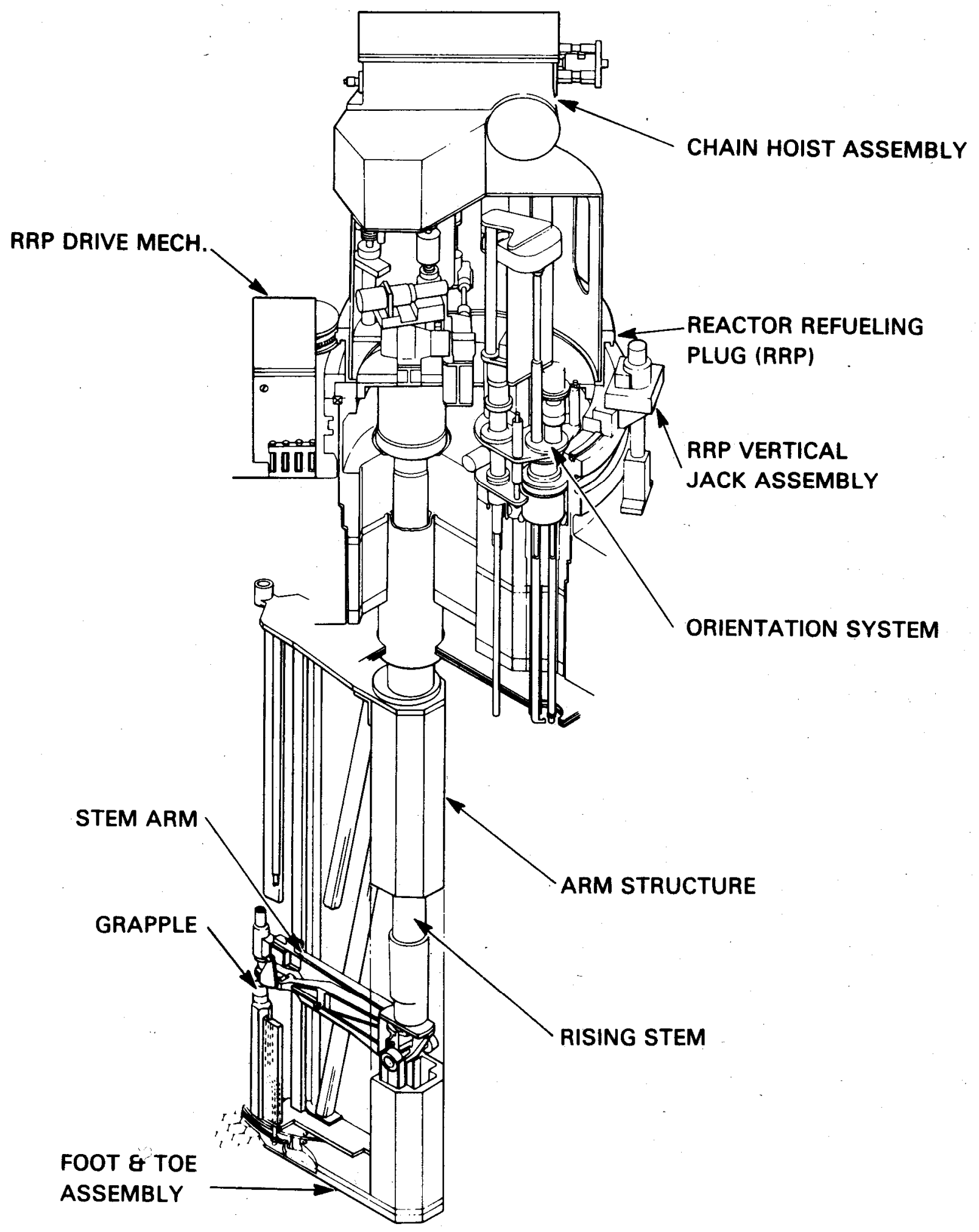

Figure A11. In-Vessel Handling Machine. 


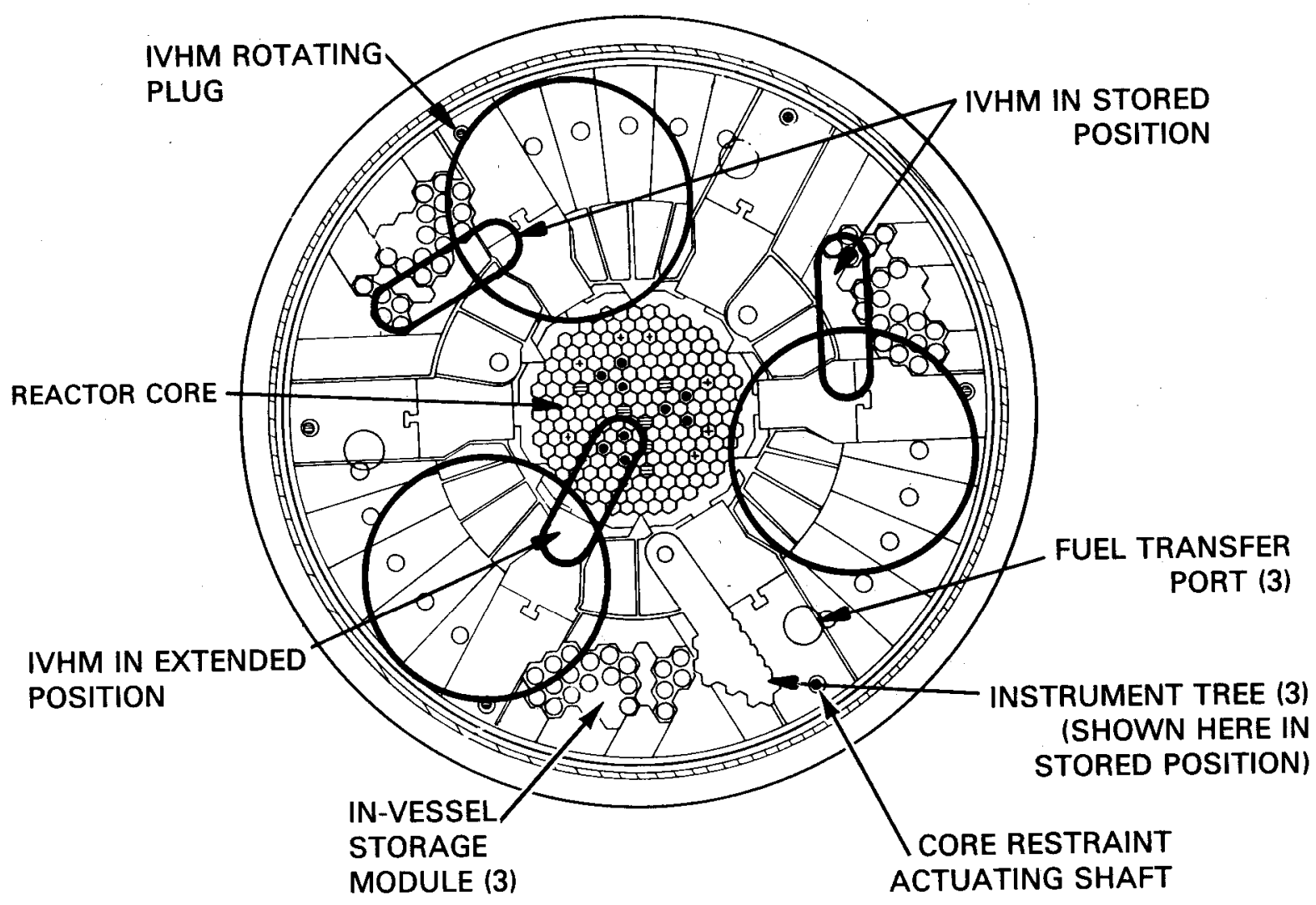

Figure A12. Plan View Showing Locations of In-Vessel Handling Machines. 


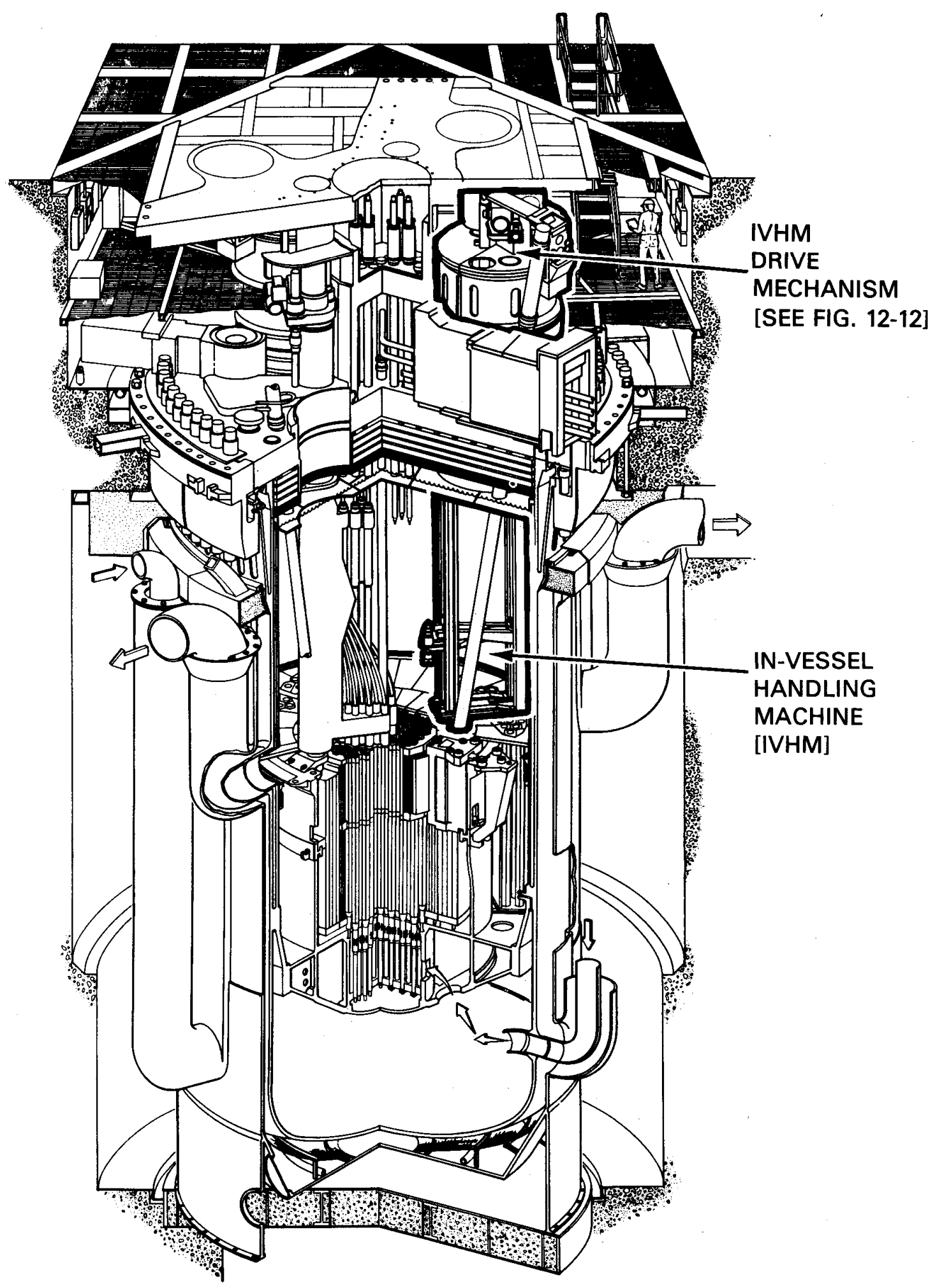

Figure A13. Reactor Cutaway Showing In-Vessel Handling Machines. 


\section{System Thermal Profile (Ref. 5)}

In the routing of core components and test assemblies through the FFTF fuel handling system, the assemblies see a variety of environmental temperatures in the various machines and facilities, i.e., a repository such as IDS, TACS, etc. In general, the assemblies going into the reactor are heated and those being removed are cooled. The process is discontinuous, however, because each facility and machine must perform either additional functions or the same function in a different way. Further, the transfer between the machine and facility must be a controlled operation. Therefore, design points and temperature ranges have been imposed on each item of equipment to provide a nominal thermal profile as shown in Figure A14. This figure is used to permit visualization of the temperature conditions which are intended and expected. There are some approximations as the figure covers many diverse conditions encompassed by normal operation of the system. For example, on the preirradiation side of the figure, TACS is not shown and those incoming test assemblies will not pass through IDS, but the temperatures for the test assemblies will be within the range shown. Even if the incoming assembly is a recycled test assembly, and therefore, has some decay heat, the temperatures are expected to be nominally as shown. In the center of the figure, the reactor temperature values indicated are obtained from the reactor system design description or from reports by the reactor designer, but are shown here more as reference indicators for the right hand side of the figure which covers removal of the core components and test assemblies from the core. The CLEM transfer from the core to IDS is a transient condition with three cases indicated. As is realistically shown, longer transfer times resulting in steady state temperatures will not compromise the assemblies, and the cases shown represent maximum conditions. Storage in IDS for all but the maximum decay power assemblies (drivers or test assembly) will be nominally $400^{\circ} \mathrm{F}\left(204^{\circ} \mathrm{C}\right)$; however, IDS does have an obligation to preserve test data following irradiation.

The next location for the test assemblies would be the IEM Cell where the assemblies are broken down into pins. The same temperatures apply as in IDS, but are expected to be requirements (presently undefined) which will be specified by the experimenter. Therefore, the postirradiation conditions for CLEM and the IEM Cell are not shown. The remaining portion of the figure shows the removal of irradiated fuel (drivers or pins) intended for storage. Few limits have been identified for this fuel and cladding. As indicated, the $1.4 \mathrm{~kW}$ assemblies will follow the nominal profile, but due to the many variables involved, temperatures could be higher. The temperatures need to be limited only to the extent of safety. 


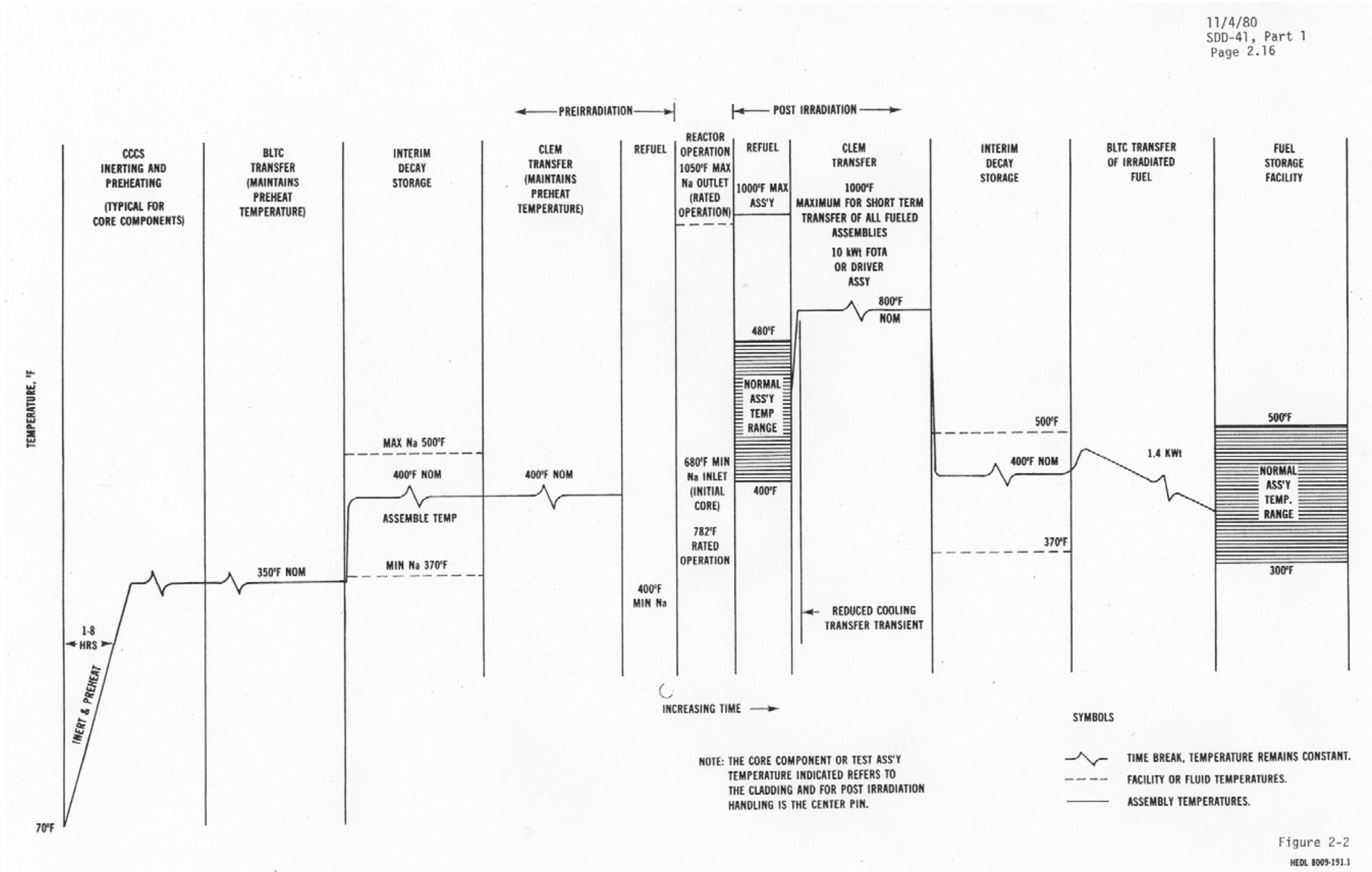

Figure A14. Thermal Profile for Fuel and Test Assemblies Handling (SDD-41). 


\section{Appendix B}

\section{CRBRP Fuel Handling System: Summary Description}

The design and performance characteristics of the Clinch River Breeder Reactor Plant (CRBRP) fuel handling system have been reviewed for relevance to the proposed Liquid Salt-Very High Temperature Reactor (LS-VHTR). This summary provides a description of the CRBRP fuel handling system and its operation.

CRBRP was designed and licensed, but not constructed. However, it was designed with strong reliance on FFTF experience, taking into account the CRBRP mission of power production, in contrast to the FFTF mission of fuel testing. (The CRBRP mission required relatively infrequent refueling outages of minimum duration, during which a large fraction of the core was refueled. In contrast, the FFTF mission required relative frequent outages during which both driver fuel and test assemblies were handled). The CRBRP fuel handling design may be viewed as an evolutionary development of the FFTF fuel handling design.

\section{CRBRP Fuel Handling System (Refs. 6, 7, 8)}

The fuel handling system provides for replacement of the reactor core components, including fuel, blanket, control, reflector, and restraint assemblies. The system consists of the facilities and equipment needed to accomplish the normal scheduled refueling operations, as well as all other functions incident to handling of core components. (These latter functions include receiving and unloading of new core components, inspection, temporary storage and conditioning under sodium, transfer of both new and spent core components between storage facilities and the reactor, transfer of core components within the reactor, removal and examination of spent core components, and preparation and loading for shipment off-site).

Refueling operations involve transfer of core components between positions within the reactor vessel, and between the reactor and the ex-vessel storage tank (EVST). Refueling operations can be accomplished only with the reactor shut down.

A view of the fuel handling system general arrangement is shown in Figure B1. New fuel assemblies arrive at the plant in shielded and cushioned containers. These core components are unloaded and inspected in a shielded new fuel handling facility located in the reactor service building (RSB). Upon acceptance of a core component, it is stored in a sub-critical array in a storage facility located in the floor of the new fuel handling facility.

In for preparation for the refueling cycle, new fuel assemblies are removed from the storage facility in a shielded transfer machine and inserted into a gas filled thimble in EVST. During the course of this operation, the air atmosphere in the shield transfer cask is exchanged for an inert, dry argon atmosphere which is compatible with the liquid sodium environment in the EVST. The new core components are loaded into the EVST at $475^{\circ} \mathrm{F}\left(246^{\circ} \mathrm{C}\right)$ until a reactor reload worth of fuel has been accumulated for refueling. 


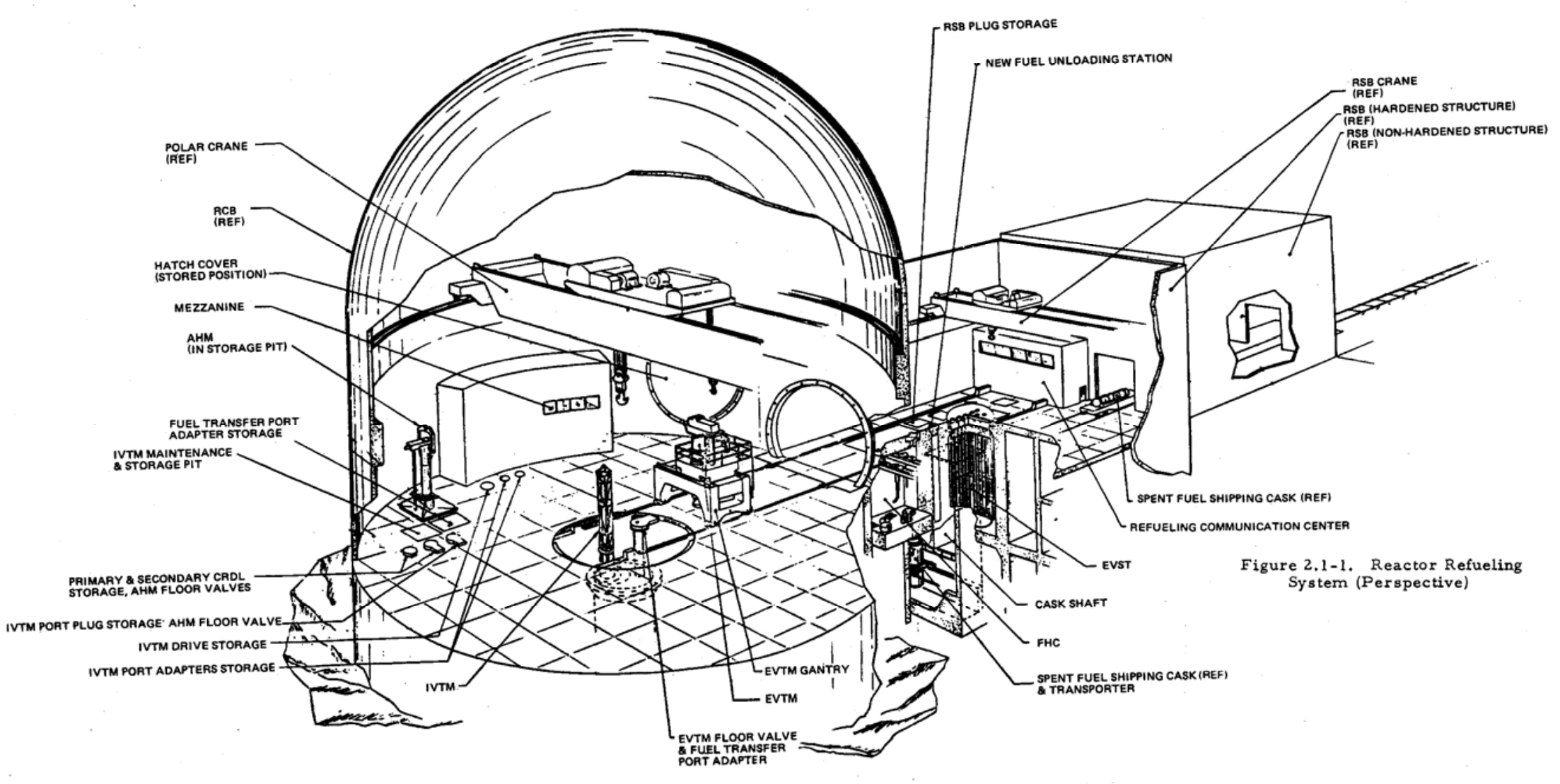

Figure B1. CRBRP Reactor Refueling System. 
After the reactor is shut down, the ex-vessel transfer machine (EVTM) transfers a new fuel assembly, in a sodium filled core component pot (CCP), from the EVST to the reactor through a $44^{\prime} 6$ " hatch in the reactor containment building (RCB) wall. When the new fuel assembly arrives at the reactor, it is discharged from the EVTM into a transfer position on the periphery of the reactor core.

At this point, the new core component is available for handling by the in-vessel transfer machine (IVTM). The IVTM withdraws a spent fuel assembly from its position in the reactor core and deposits it into an empty CCP in a transfer position. The IVTM then picks up a new fuel assembly from the transfer position and inserts the assembly into position in the reactor core. Horizontal motion of the IVTM is accomplished by means of triple rotating plugs mounted in the reactor head (See Figure B2). By rotating these plugs in sequence, the IVTM, which is a simple straight pull tubular device mounted on a port in the inner-most rotating plug, can be indexed over any core or transfer position in the reactor.

When a spent core component is available in a transfer position, the EVTM withdraws the component in a CCP from the reactor vessel and transfers it to the EVST. The EVTM mates to a port in the large rotating plug for access to the fuel transfer positions inside the reactor vessel.

After a suitable decay period, spent fuel can be removed from the EVST and prepared for shipment from the plant.

\section{$\underline{\text { System Functions }}$}

The major equipment and facilities, and the general arrangement of the reactor refueling system are shown in perspective in Figure B1. The majority of the equipment and facilities are located in the Reactor Service Building (RSB), which is adjacent to the Reactor Containment Building (RCB). Important fuel handling facilities and equipment located in the RSB include the ExVessel Storage Tank (EVST), the fuel handling cell (FHC), new and spent fuel unloading and loading facilities, miscellaneous storage facilities, and a communications center from which refueling and other fuel handling operations are coordinated. Equipment and facilities located in the RCB are limited to those involved with fuel handling in the reactor; they include the InVessel Transfer Machine (IVTM), the Auxiliary Handling Machine (AHM), and miscellaneous storage facilities.

Fuel movement between buildings is accomplished during reactor shutdown using an Ex-Vessel Transfer Machine (EVTM) mounted on the EVTM gantry-trolley. The EVTM and gantry-trolley pass through the RCB equipment hatch, which is opened for these operations. The EVTM and gantry-trolley remain in the RSB during reactor operation.

The EVST is a large, two-tier, sodium-filled storage tank, with a capacity to store two refueling loads of heat-producing (fuel or blanket) assemblies, and also has sufficient capacity to store the heat-producing assemblies from a complete core unloading. Low-heat-producing assemblies may be stored in either the EVST or the FHC. The EVST upper tier positions are sufficient to handle a single refueling load. 


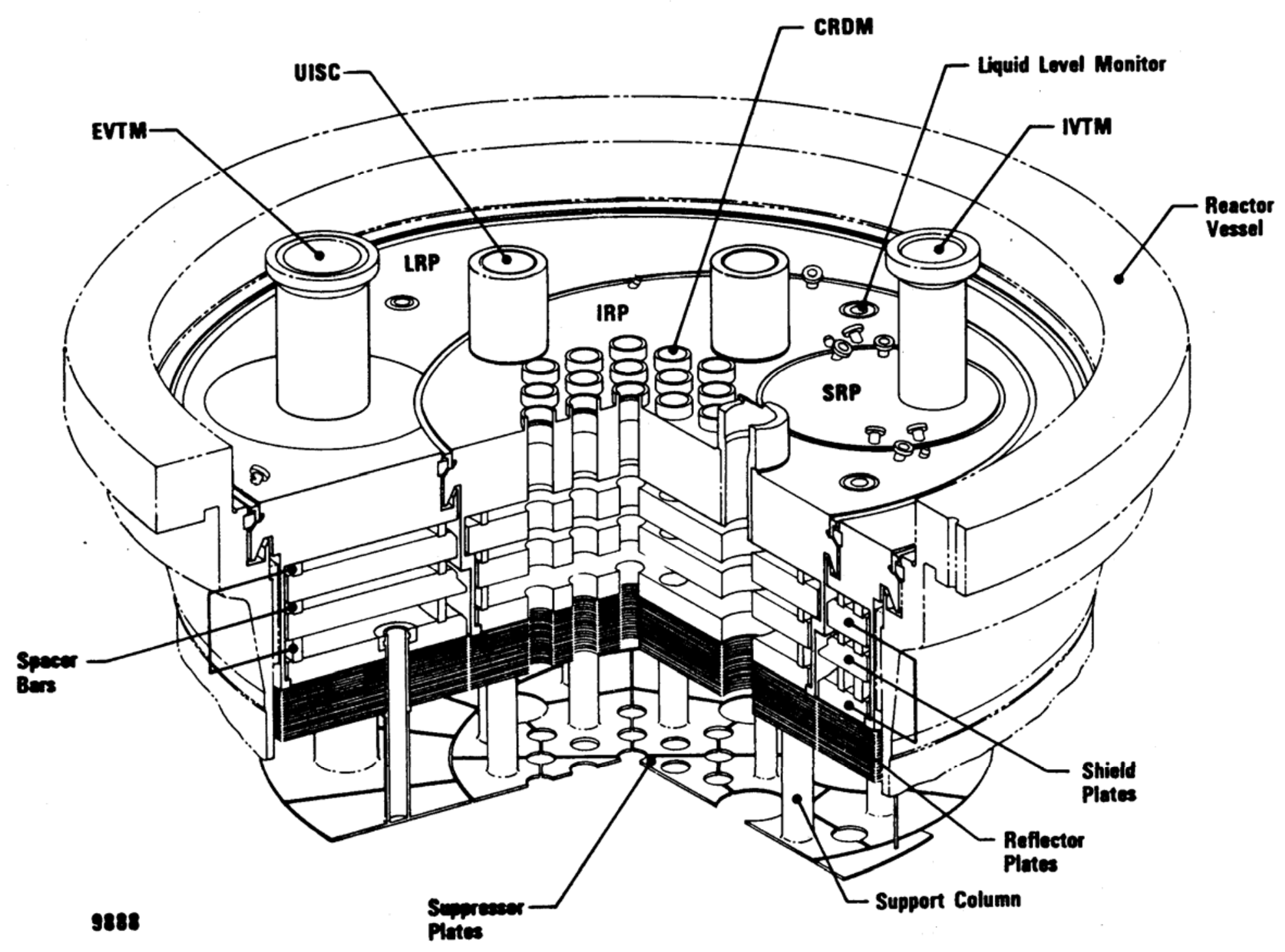

Figure B2. CRBRP Reactor Vessel Head Rotating Plugs. 
The IVTM is a vertical, push-pull machine, mounted on the small rotating plug which forms part of the triple rotating plug assembly in the head of the reactor vessel. By grappling a fuel assembly, raising it above the core with the IVTM, and rotating the plugs, fuel is transferred from a core position to a transfer position within the reactor vessel, where it is deposited into a core component pot, which is then picked up and removed by the ex-vessel transfer machine.

The EVTM is a heavily shielded machine which provides either heating or cooling, as required, during transfer of new or irradiated fuel between the reactor and ex-vessel fuel handling facilities. All refueling operations by the EVTM are accomplished with the fuel in a sodium filled thimble, called a core component pot (CCP). The CCP is necessary to assure adequate cooling of spent fuel within the machine.

The sequence for handling fuel begins with receipt of new fuel on site by truck. The fuel assemblies are transported in lightly shielded, single-assembly shipping containers. The containers are removed from the truck and placed in a laydown area. The containers are checked to verify that the shock indicators have not been displaced. The RSB crane is used to the container to a vertical attitude and place it into one of two new fuel unloading stations. The stations are located between the EVST and FHC and are within the coverage of the EVTM.

Following inspection, the atmosphere of the shipping container is changed from air to argon to be compatible with the EVTM and EVST. The EVTM is mated with the shipping container through an adapter assembly which is a part of the new fuel unloading station. The EVTM removes the new core assembly and transfers it to the EVST. The core assembly is placed in a preheat tube in the EVST, where it is slowly heated in argon to approximately the same temperature as the sodium in the tank. After preheating, the assembly is transferred to a sodiumfilled core component pot (CCP) in one of the storage positions in the tank. This transfer is also accomplished by means of the EVTM.

Prior to reactor shutdown for refueling, a number of preparatory operations are conducted, so that reactor downtime for refueling is minimized. All equipment and facilities to be used in the refueling operations are checked for functionality. In addition to checkout, actual equipment placement can begin in the RSB. This includes placement of floor valves over two EVST fuel transfer ports, removal of the port plugs by the EVTM, and transfer of the plugs to the RSB plug storage facility.

Twenty days have been allotted for an average reactor refueling. This begins with reduction of reactor power from $100 \%$ to the power level from which the reactor is shut down. After the reactor is shut down, the equipment hatch between the RCB and the RSB is opened. The sodium in the reactor vessel is cooled down to refueling temperature, the control rod drive lines are disconnected from the absorber assemblies and raised, and the upper internals are raised, permitting rotation of the plugs in the reactor head. Concurrently, the reactor cover gas is purged and purified to reduce radioactivity levels in the gas to a very low level. This completes the preparations for refueling, and permits reactor refueling operations to begin.

Reactor refueling operations during reactor shutdown begin with installation of adaptors and floor valves over the reactor fuel transfer port and the IVTM port in the reactor head, using the 
RCB polar crane. The reactor port plugs are then removed by the AHM and the EVTM and are placed in plug storage locations within the RCB and the RSB. The IVTM in-vessel section is then installed, again using the AHM. At this point, the floor valve and adaptor on the IVTM port are removed and the IVTM drive section is installed; all these operations are performed by the polar crane. The IVTM then undergoes a simple checkout, to assure that all electrical and gas services have been connected properly, followed by a check in conjunction with the reactor rotating plugs, to assure that core positions can be properly indexed. This completes reactor refueling systems preparations for refueling.

The reactor is now ready for refueling. First, the EVTM moves an empty (but sodium-filled) $\mathrm{CCP}$ from the EVST to the reactor. At this point, the EVTM removes a new core assembly in a sodium-filled CCP from the ex-vessel storage tank, while the IVTM removes a spent core assembly from the core and deposits it in the empty CCP located in a transfer position outside the core, but still within the reactor vessel. The EVTM then places the new core assembly and $\mathrm{CCP}$ in a second transfer position inside the vessel, the rotating guide tube rotates to the first transfer position, and the EVTM removes the spent core assembly in its sodium-filled CCP from the first transfer position.

During this time, while the EVTM is at the reactor, the IVTM and rotating plugs must remain stationary. The EVTM then moves away from the reactor to deposit the spent core assembly and CCP in the EVST, while the IVTM, operating in conjunction with the rotating plugs, installs the new core assembly in the open core lattice position. These operations are repeated until the refueling is completed.

After refueling is completed, operations terminating refueling begin, and are essentially the reverse of the preparation operations. The upper internals are lowered, control rod drive lines are lowered and reconnected, and the reactor instrumentation is checked out. The equipment hatch is then closed and leak checked, and the reactor is made critical and returned to full power.

After spent fuel has decayed for about 100 days in the EVST, it may be loaded into the spent fuel shipping cask. Control, radial shield, and some low power blanket assemblies can be shipped off site before the 100-day cooling period, but fuel and high-power blanket assemblies are held until they decay to within the spent fuel shipping cask heat rejection capability.

\section{System Components}

$\underline{\text { In-Vessel Transfer Machine (IVTM) }}$

The IVTM has following operational capabilities:

1. Grapple and release core assemblies

2. Raise and lower core assemblies

3. Provide hold-down of adjacent core assemblies

4. Uniquely identify core assemblies

5. Orient and center core assemblies for insertion in the core. 
The IVTM consists of two principal subassemblies-the in-vessel section, and the ex-vessel or drive section (See Figure B3). The in-vessel section contains the grapple, centering device, identification mechanism, the hold-down mechanism, and the seals for reactor cover gas containment. The ex-vessel section contains the drive equipment which powers the in-vessel section mechanisms. The IVTM is a straight push-pull machine; horizontal translation is accomplished by rotation of the plugs in the reactor head.

The lower portion of the in-vessel section is exposed to reactor sodium and cover gas, and must be installed and removed using the AHM, which provides a shielded, inert gas environment. The drive section is exposed only to the RCB air environment, and can be installed using the polar crane. All parts requiring routine service or inspection are located on the drive section and on the in-vessel section above the reactor head to provide for easy accessibility. The dynamic elastomeric seals, which are located in the upper end of the in-vessel section, are continuously monitored, but any necessary replacement of these seals will be done at the facility provided for storage of the IVTM in-vessel section.

The major performance characteristics of the IVTM are summarized in Table B1.

Table B1. IVTM Performance Characteristics.

$\begin{array}{ll}\text { Design Concept } & \begin{array}{l}\text { Straight push-pull, rising stem, } \\ \text { with triple rotating plugs }\end{array} \\ \text { Grapple Vertical Stroke } & \sim 18 \mathrm{ft} \\ \text { Core Holddown Stroke } & \sim 3-1 / 2 \mathrm{ft} \\ \text { Grapple Vertical Speed (approx.) } & \sim 1 \text { to } \sim 15 \mathrm{fpm} \\ \text { Grapple Vertical Load } & \\ \quad \text { Normal Operational Limit } & 1000 \mathrm{lb} \text { pull } \\ & 1000 \mathrm{lb} \text { push } \\ \text { Maximum Operational Limit } & 4300 \mathrm{lb} \text { pull } \\ & 3000 \mathrm{lb} \text { push } \\ \text { Design Capability } & 5000 \mathrm{lb} \text { pull } \\ & 5000 \mathrm{lb} \text { push }\end{array}$

\section{Auxiliary Handling Machine (AHM)}

The AHM (Figure B4) is a single barrel handling machine which provides an inert atmosphere and radiation shielding for transferring sodium-wetted radioactive components between the reactor and storage facilities within the RCB. These operations are primarily involved in preparation for (and termination of) refueling: (1) removing the IVTM port plug and installing the IVTM in-vessel section, and (2) returning these items after refueling. The AHM is also used to support maintenance functions such as removal and installation of control rod drive lines and core inlet modules. The AHM is similar in concept to the EVTM, but it has been simplified, due to the less demanding requirements of the components it handles. The major differences are: (1) no radioactive decay heat, (2) much lower radiation source strength, (3) less sodium drippage, and (4) the much lower requirement for speed of operation. The AHM is used only within the $\mathrm{RCB}$, transported from station to station by the polar crane. 


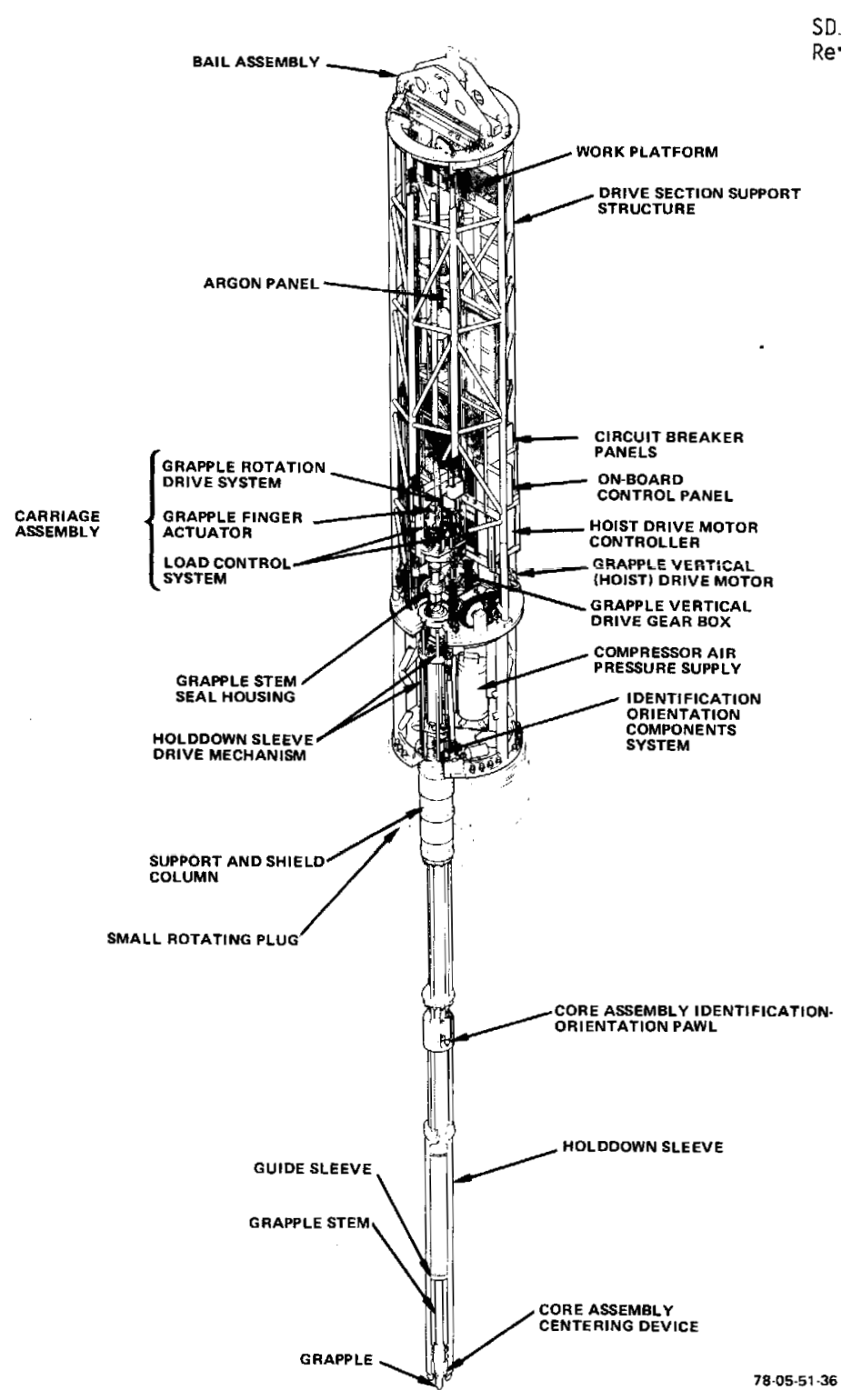

Figure B3. In-Vessel Transfer Machine (IVTM).

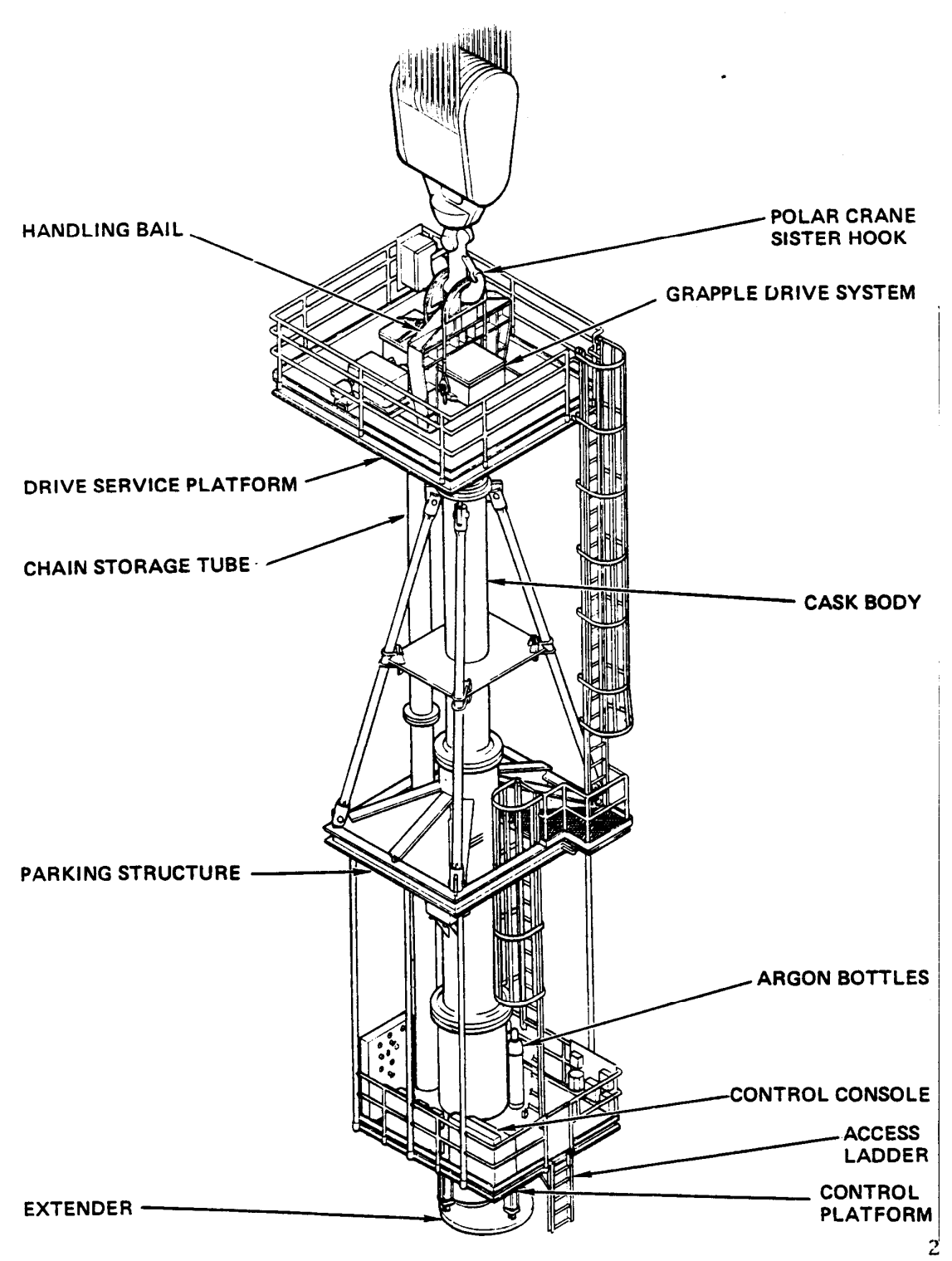

Figure B4. Auxiliary Handling Machine. 


\section{$\underline{\text { Floor Valves }}$}

The function of the floor valve (Figure B5) is to seal a reactor or other facility access port during various phases of the refueling operation when the port plug is removed. The floor valve prevents the release of radioactivity-contaminated gas, and shields the building operating floor environment from radiation. The floor valve is a portable item of equipment. Two basic sizes are used, one for the transfer of core assemblies (used with the EVTM), and another with a larger opening (used with the AHM), for the transfer of the in-vessel section of the IVTM and other components. Both types have the same basic design, except for the interior opening size and differences in the thickness of the shielding surrounding the central cavity. To simplify nomenclature, the portable floor valves are identified as EVTM floor valves and AHM floor valves, depending on the principal mating machine. The AHM floor valves are normally used at three locations in the RCB during refueling - the IVTM port on the reactor head, the IVTM port plug storage pit, and the IVTM storage and maintenance facility. These valves are also stored in the RCB. The floor valve design is similar to that developed for the FFTF program.

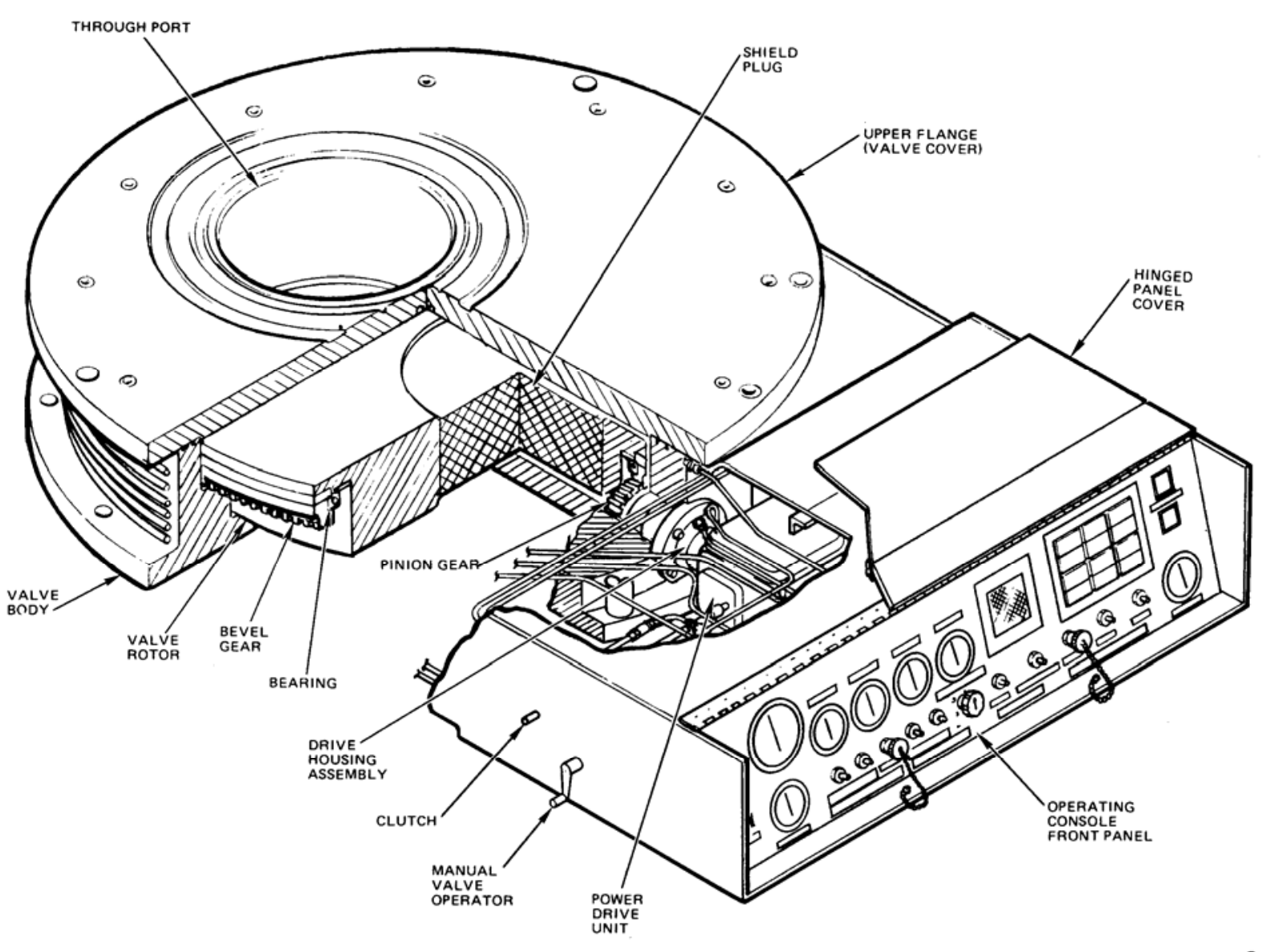

Figure B5. AHM Floor Valve. 


\section{Port Adaptors}

The port adaptor provides an isolated shielded volume connecting a port in a facility located below operating floor level and a floor valve placed at floor level, through which contaminated and/or radioactive components may be safely transferred. Adaptors are sized for specific applications, and may be generally described as hollow, open-ended, thick-walled stainless steel cylinders, equipped with flanges and seals at each end. One end mates with and seals to a facility port, while the other end mates with and seals to a floor valve. Figure B6 shows the IVTM port adaptor installed on the reactor small rotating plug.

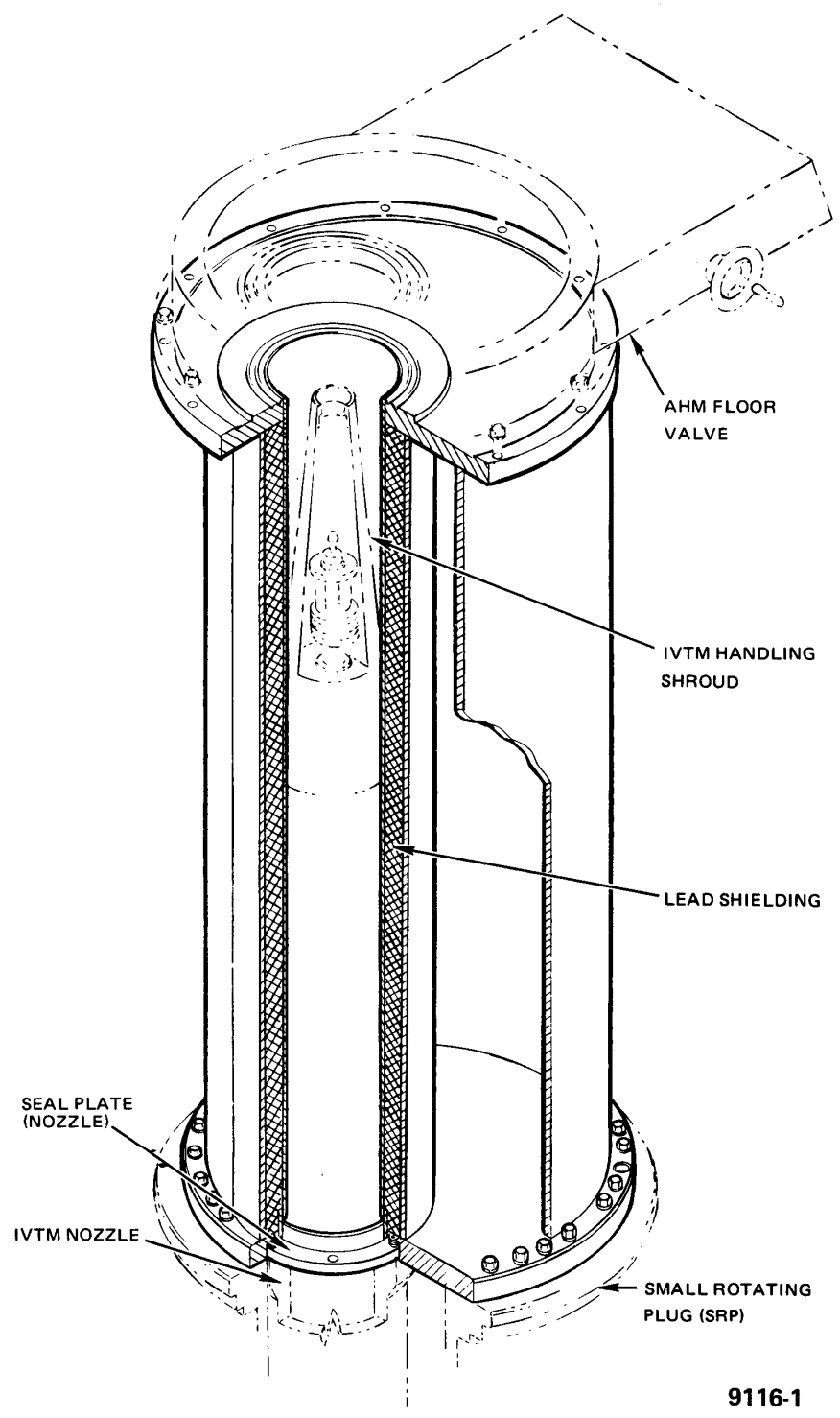

Figure B6. IVTM Port Adaptor. 


\section{$\underline{\text { Ex-Vessel Transfer Machine (EVTM) }}$}

The primary function of the EVTM is to handle and transfer both new and irradiated core assemblies. The EVTM implements the primary function by the following operational capabilities:

1. Grapple and release core assemblies, core component pots, and port plugs

2. Raise and lower core assemblies, core component pots, and port plugs

3. Provide containment of radioactive cover gas

4. Maintain an argon environment

5. Maintain preheat temperature for new core assemblies

6. Provide cooling for spent core assemblies

7. Provide radiation shielding

The EVTM, shown in Figure B7, is a shielded, inerted, single barrel machine. The major performance characteristics of the EVTM are summarized in Table B2. The machine has provisions for maintaining preheat of new core assemblies and for cooling irradiated core assemblies. The EVTM is mounted on a trolley which is positioned on rails on top of a gantry (Figure B8). The gantry moves on crane rails between the RCB and the RSB. The trolley rails are perpendicular to the gantry rails, allowing complete indexing of the EVTM.

\section{Table B2. EVTM Performance Characteristics}

Design Concept
Method of Transport
Heating
Cooling
$\quad$ Design Capability
Grapple Drive and Actuation
Grapple Vertical Force Capability
Grapple Speed
Components Handled

Cold wall, single barrel

Gantry-Trolley

Electrical

Cold wall

$20 \mathrm{~kW}$

Chains

$\sim 3500 \mathrm{Lb}$ pull

$\sim 500 \mathrm{lb}$ push

$\sim 24 \mathrm{ft} / \min (\max$.

Core component pots, core assemblies, port plugs

Irradiated core assemblies are handled only in sodium-filled core component pots. Cooling of the EVTM is accomplished by a cold-wall concept consisting of an axial-finned tube, which also provides containment for the argon cover gas, and a forced convection air circulation system. The cooling concept is illustrated in Figure B9. Heat from the 3-ft high fueled region of the spent fuel assembly is distributed over the $\sim 15$-ft length of the core component pot by natural convection of the sodium in the pot. Heat is transferred to the cold wall primarily by thermal radiation, and secondarily by conduction across a stagnant argon-filled gap. The cold wall is cooled by forced convection of ambient air circulated past the axial fins. This cooling system has a blower with the capacity to circulate sufficient air to maintain fuel cladding temperature at less than the normal limit. In case of blower failure or complete loss of all power, natural convection air flow is sufficient to maintain fuel cladding temperatures below the faulted limit. 


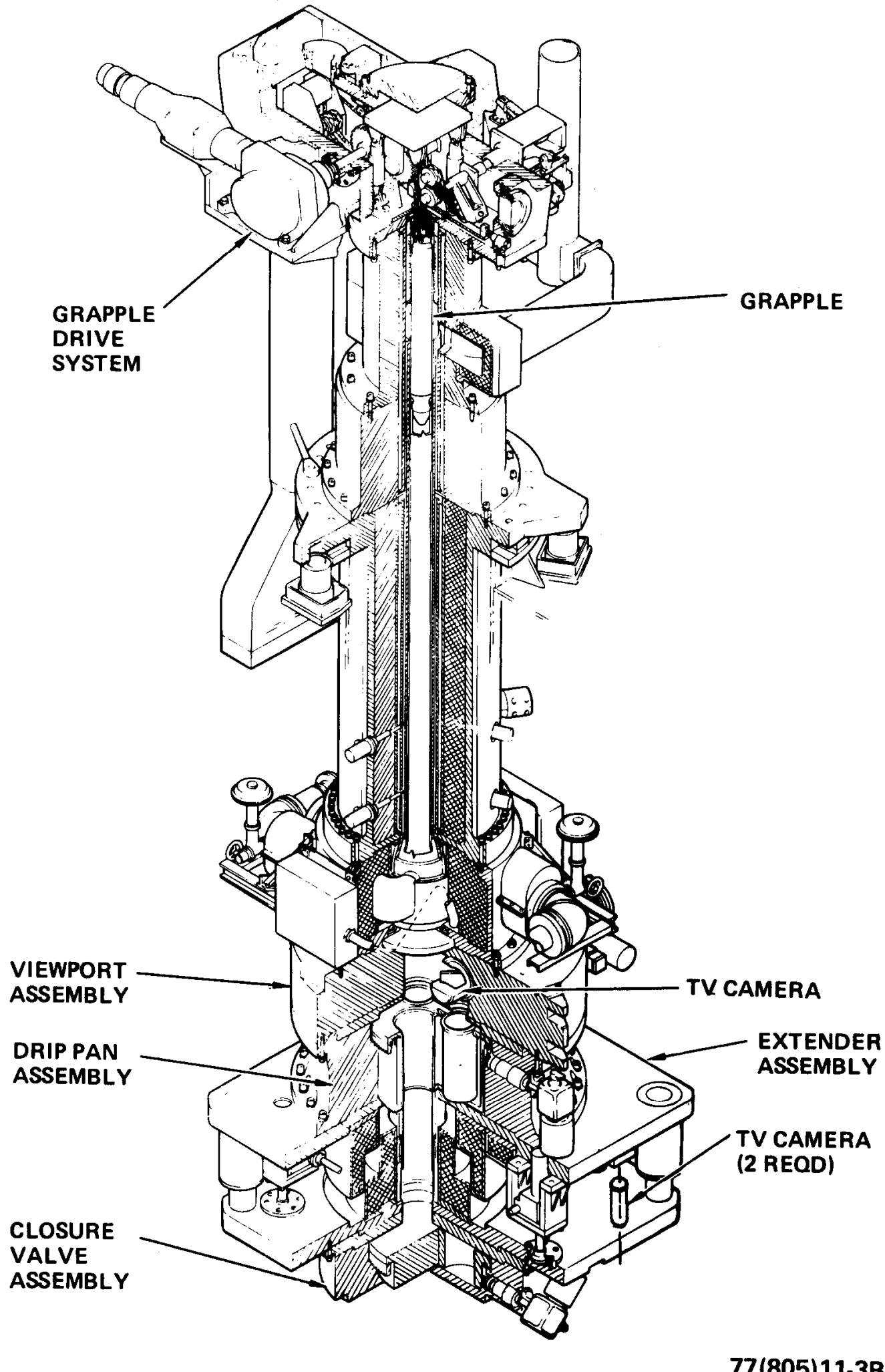

Figure B7. Ex-Vessel Transfer Machine (EVST). 


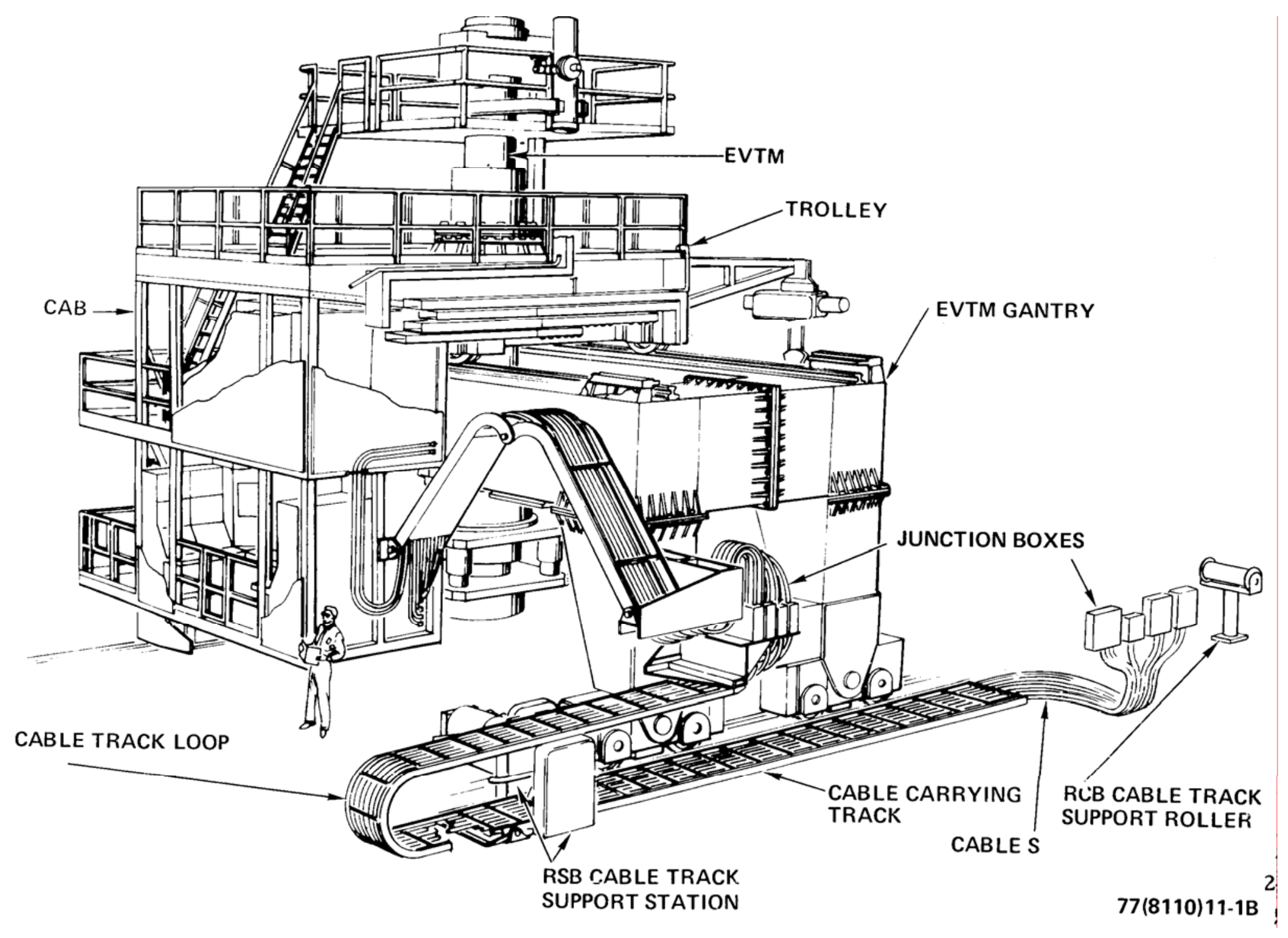

Figure B8. EVTM Gantry-Trolley. 

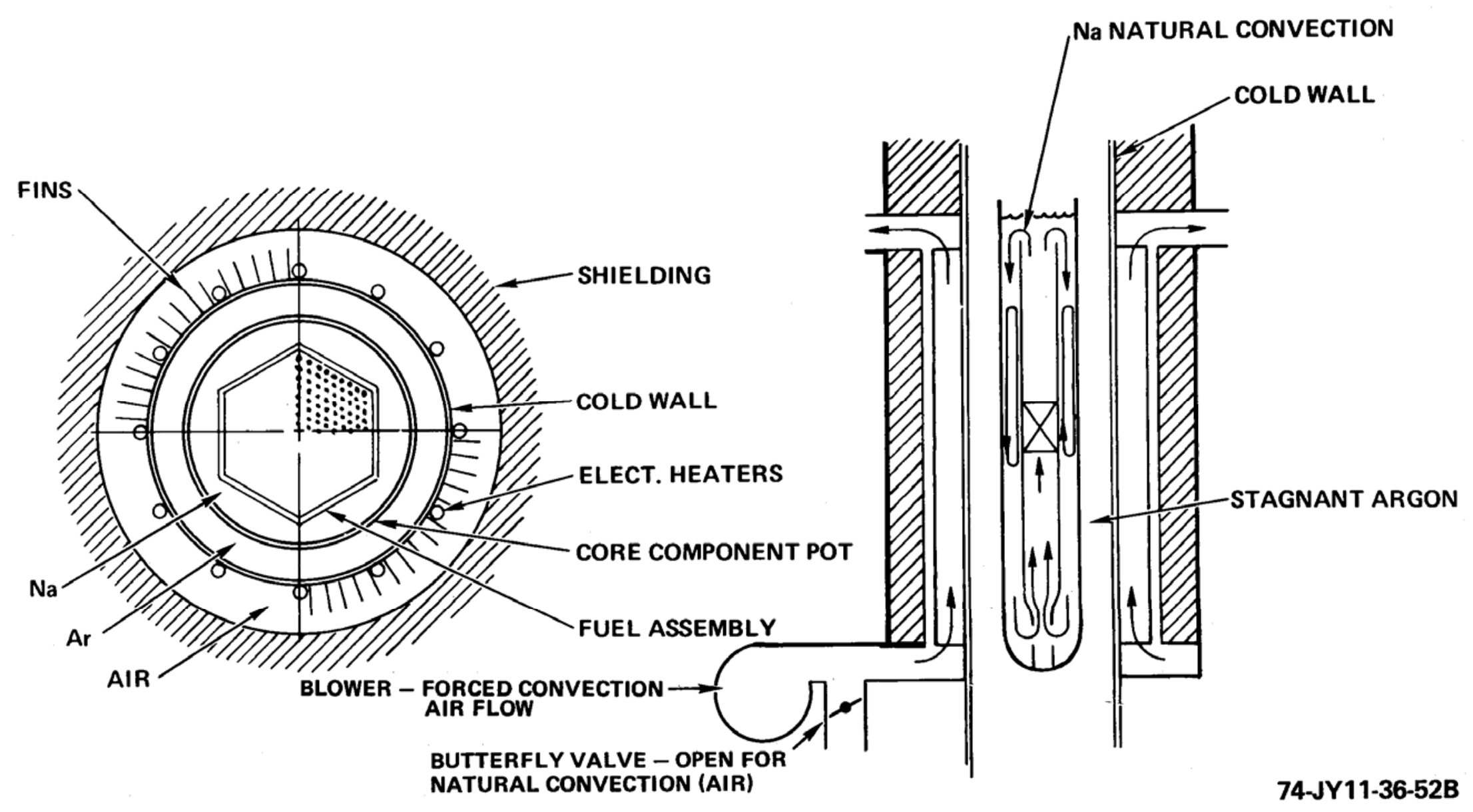

Figure B9. EVTM Cold-Wall Cooling Concept. 


\section{Core Component Pot (CCP)}

The function of the CCP is to provide a sodium environment for core assemblies in transit between the reactor vessel and fuel handling facilities, in order to increase heat transfer to cool irradiated fuel assemblies. The CCP (see Figure B10) is a tubular steel container, closed at the bottom, with a handling socket at the upper end which can be grappled by the EVTM or the fuel handling cell grapple. Near the top of the CCP is a siphon assembly, designed to remove a predetermined volume of sodium at the time the pot is raised above the facility sodium level, thereby allowing for subsequent sodium thermal expansion due to the maximum powered irradiated fuel assembly decay heat. This feature prevents overflow and greatly reduces sodium drippage and splash, with their consequent operational and contamination problems. The CCP is used to receive core assemblies during in-vessel transfer, to transport them in the EVTM, and to store them in the EVST and FHC. A CCP is needed for every storage position in the EVST.

\section{$\underline{\text { Reactor Fuel Transfer Port Adaptor }}$}

The reactor fuel transfer port adaptor (see Figure B11) consists of two assemblies, an upper adaptor and a lower adaptor. The steel lower adaptor is semi-permanently bolted to the reactor head at the reactor fuel transfer port. The removable steel and lead shielded upper adaptor is used during refueling, extending from the lower adaptor to the bottom of the floor valve which is positioned on top of the reactor fuel transfer port and extends from the reactor head to the bottom of the floor valve, which is located at the elevation of the RCB operating floor. It serves as an extension of the reactor cover gas containment and provides shielding when irradiated core components are removed from the reactor. The adaptor also guides cooling air from an air blower to a cooling insert inside the adaptor.

\section{$\underline{\text { Rotating Guide Tube (RGT) }}$}

The function of the RGT (Figure B12) is to provide a means for the EVTM to insert a new core assembly in a CCP into one of two fixed in-vessel transfer positions, and remove a spent core assembly in a CCP from the other transfer position, without requiring an EVTM decoupling recoupling procedure between these two operations. Elimination of this procedure results in a savings of several days of reactor downtime per refueling. The RGT is a straight tube with an eccentric lower end. The RGT is mounted on the top of the reactor fuel transfer port nozzle. It remains in the reactor during reactor operation and operates only during reactor shutdown for refueling. The RGT rotates about $180^{\circ}$ to locate the center of the eccentric lower section over either of two adjacent transfer positions. Any adjacent two of the five in-vessel transfer positions can be used by appropriate positioning of the large rotating plug. 


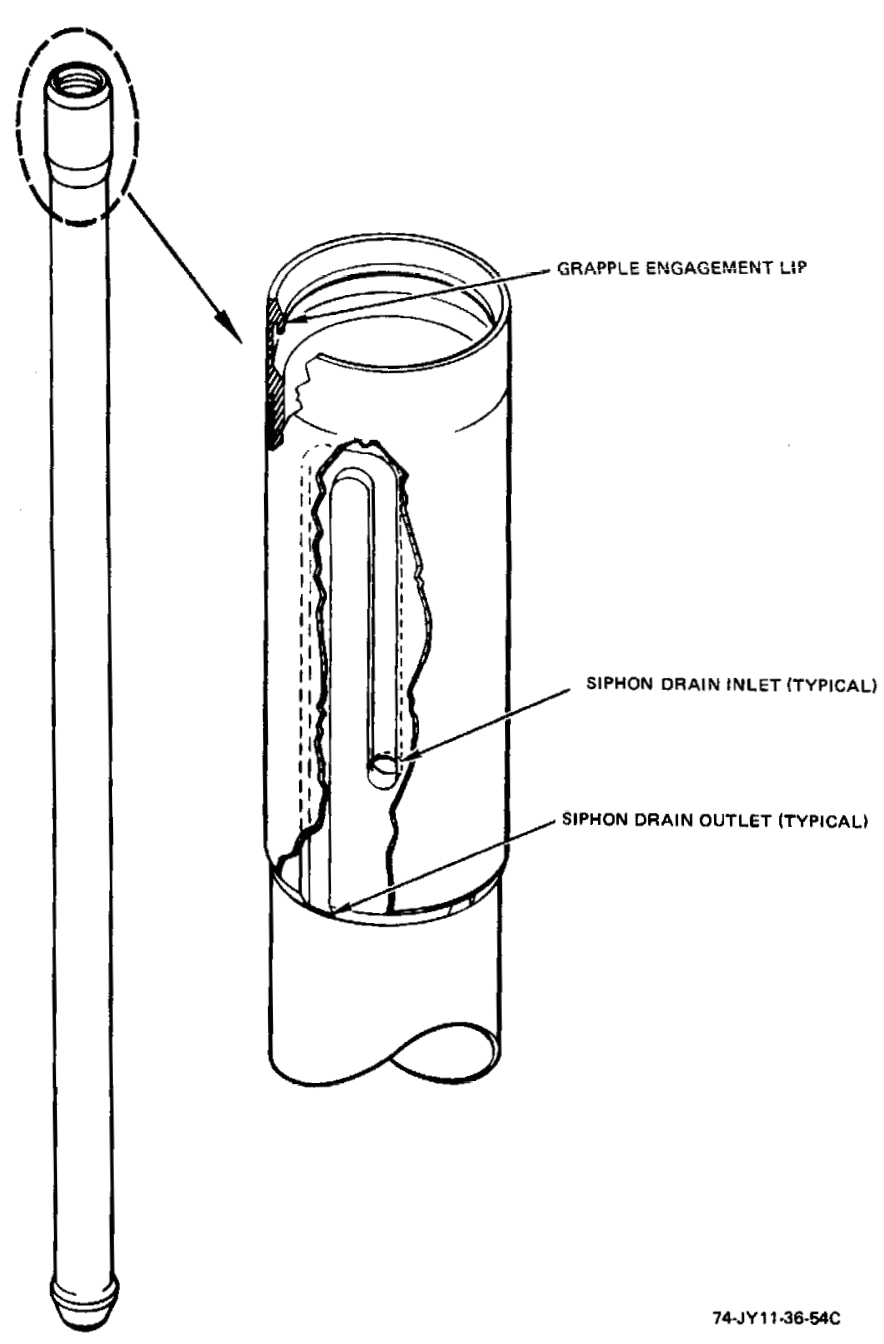

Figure B10. Core Component Pot (CCP).

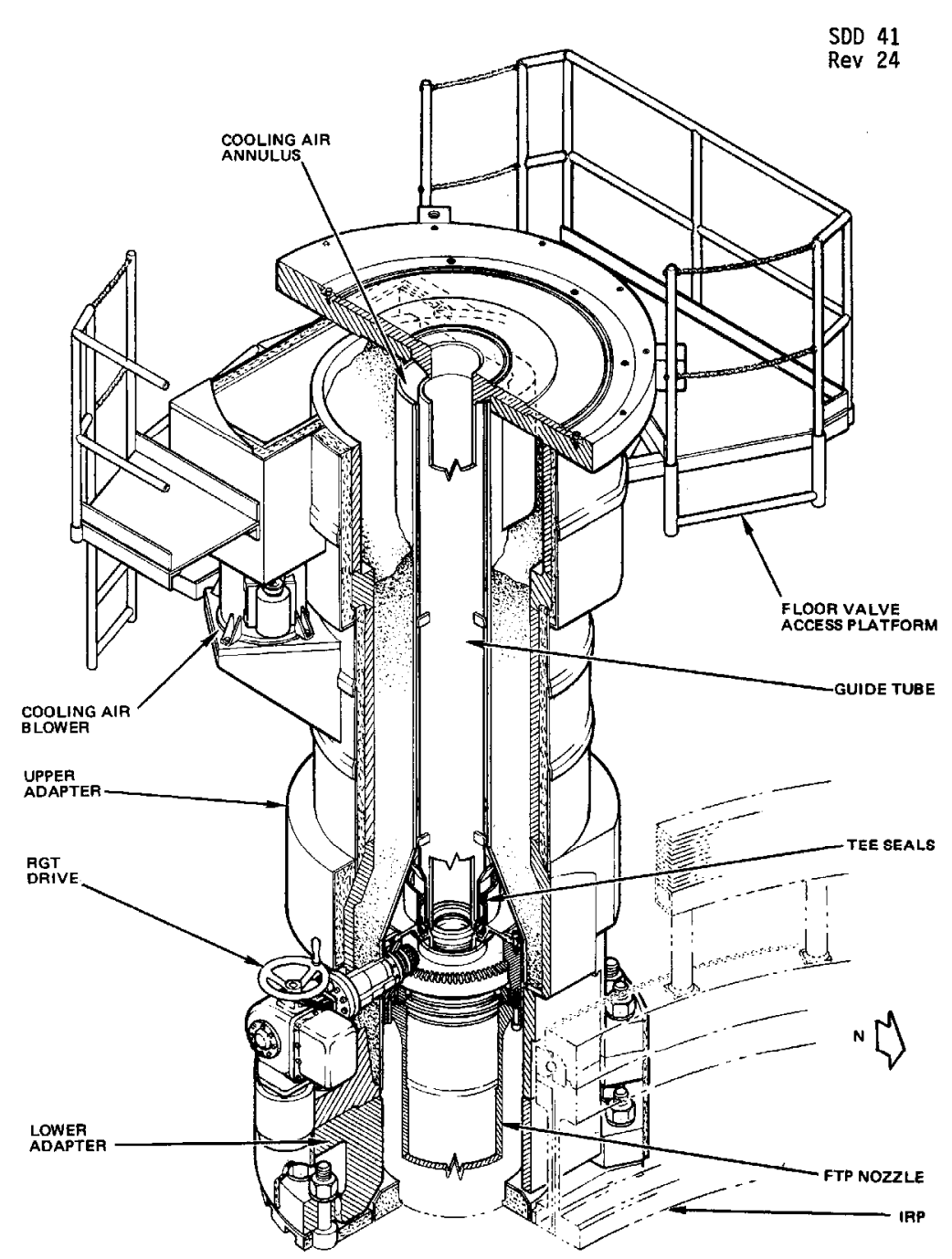

Figure B11. Reactor Fuel Transfer Port Adaptor Assembly. 


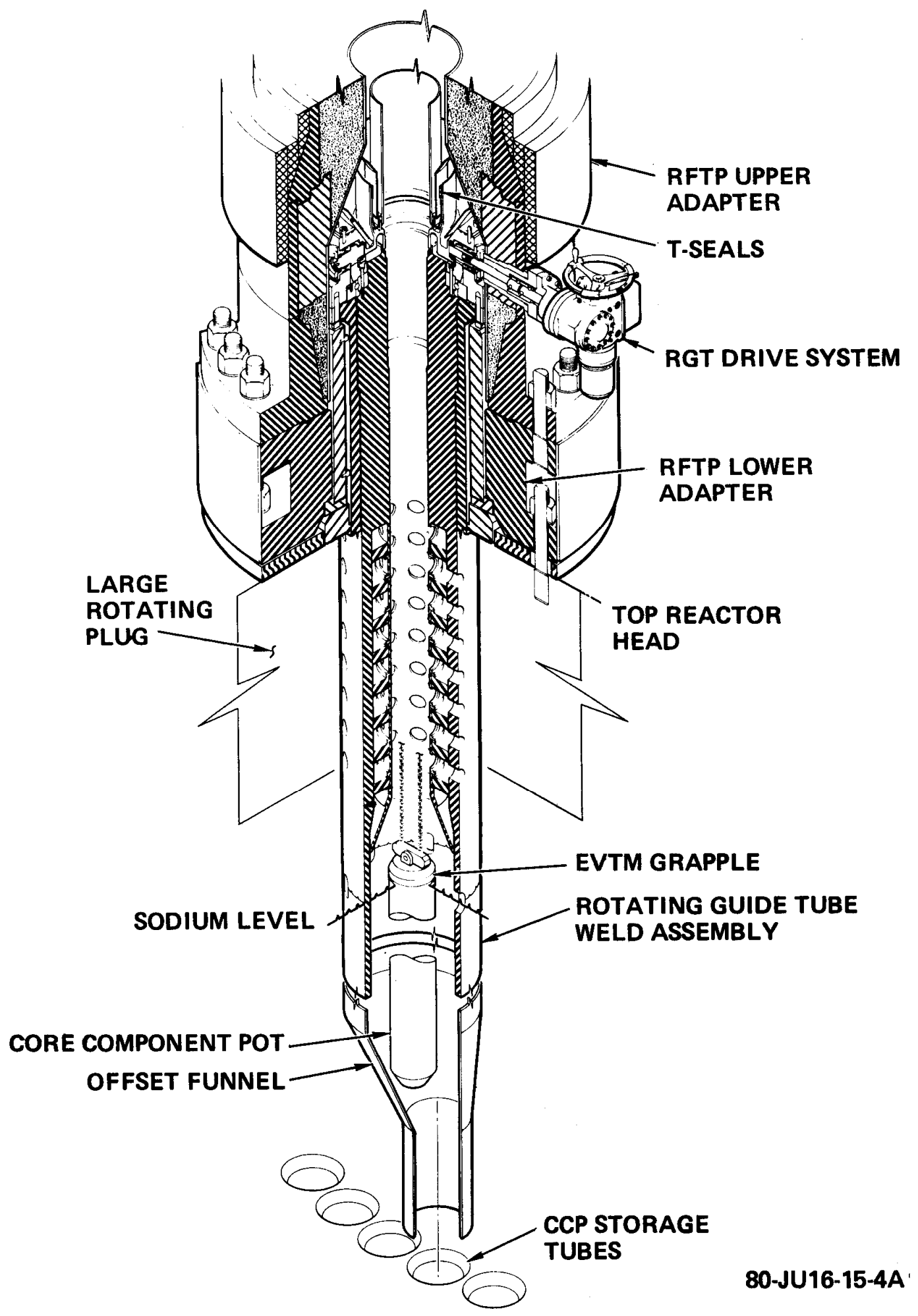

Figure B12. Rotating Guide Tube. 


\section{$\underline{\text { Ex-Vessel Storage Tank (EVST) }}$}

EVST capabilities include: 1. Preheating new core assemblies, 2. Storing new and irradiated core assemblies under sodium, 3. Cooling irradiated core assemblies, 4. Containing cover gas, 5. Providing structural support and physical separation of fuel assemblies to maintain sub-criticality, and 6. Radiation shielding.

The EVST (See Figure B13) is a sodium-filled storage facility with a two-tier rotating turntable and a fixed closure head with fuel transfer ports. The EVST is located in the RSB between the EVTM gantry rails in a nitrogen-gas filled concrete vault. The EVST performance characteristics are given in Table B3. The major EVST components and their major functions are listed in Table B4.

The storage vessel and turntable are top supported. The guard tank is bottom supported. The closure head and turntable loads are transmitted to the storage vessel flange, which in turn, transmits the loads through the storage vessel support structure to the vault concrete. No seismic restraint is required between the turntable and storage vessel.

The storage vessel is surrounded by the guard tank as a safety measure against any sodium leaks of the storage vessel, so that cooling of irradiated assemblies can be maintained. The volume between the guard tank and storage vessel is small enough to maintain a minimum safe sodium level above the core assemblies stored in the upper tier of the vessel, in the event of a gross vessel failure, and is large enough to allow for in-situ weld inspection of the storage vessel exterior surface and the guard tank inner surface by an inserted movable in-service inspection device. The outside of the guard tank is insulated and has electrical heaters.

The core assembly storage positions are cylindrical tubes, restrained and supported by grid plates in the turntable. Each storage tube holds two core component pots, one above the other. A maximum of 650 core assemblies can be stored in 9 circular rows in the EVST. A total of 668 positions are provided in the EVST design, but 18 of these are reserved for EVST neutron absorbers and are not available for core assembly storage.

Nine storage positions in various rows of the upper tier, and nine corresponding positions in the lower tier contain $\mathrm{B}_{4} \mathrm{C}$-filled neutron absorber assemblies and are inaccessible for fuel storage ${ }^{-}$ The purpose of the absorber assemblies is to limit the value of $\mathrm{k}_{\text {eff }}$ for the EVST to $\leq 0.95$.

The EVST also contains 24 dry, argon-gas-filled preheat tubes, six in each of the outer four rows of the upper tier, where new core assemblies are placed for preheating prior to immersion in the sodium. Core assembly temperatures increase at a slow rate when placed in these gas-filled positions, since heat transfer from the thimble wall to the assembly by both gas conduction and thermal radiation is minimal. Under normal conditions, the preheat tubes reduce the effective storage capacity of the EVST. In addition, each row has one vacant storage position in each tier for ease of shuffling, reducing the effective storage capacity by another 18 positions, to a usable total of $\sim 600$. In the event that the entire storage capacity is needed (e.g., in case of a complete core unloading), the preheat tubes can be removed and the vacant positions filled. 




Figure B13. Ex-Vessel Storage Tank (EVST). 
Table B3. EVST Performance Characteristics

$\begin{array}{ll}\text { Number of Storage Positions } & 650 \mathrm{t} \\ \text { Design Heat Load (see Table } 1.3 .3-1)(\mathrm{kW}) & 1800 \\ \text { Sodium Inlet Temperature }\left({ }^{\circ} \mathrm{F} /{ }^{\circ} \mathrm{C}\right) & \sim 400 / \sim 204 \\ \text { Sodium Flow Rate }(\mathrm{gpm}) & \sim 400 \\ \text { Storage Vessel Design Temperature }\left({ }^{\circ} \mathrm{F} /{ }^{\circ} \mathrm{C}\right) & 650 / 343 \\ \text { Containment Boundary Design Pressure }(\mathrm{psig}) & \pm 15\end{array}$

Table B4. EVST Major Components and Functions

Component Name $\quad$ Function

$\begin{array}{ll}\begin{array}{l}\text { Storage Vessel } \\ \text { Guard Tank }\end{array} & \begin{array}{l}\text { Contain liquid sodium } \\ \text { Contain liquid sodium and maintain safe level } \\ \text { in the event of storage vessel failure }\end{array} \\ \text { Closure Head } & \begin{array}{l}\text { Provide sealing of the cover gas, and radiation } \\ \text { shielding for RSB operating floor } \\ \text { Support core component pots, and maintain } \\ \text { sub-criticality of fuel assemblies by physical } \\ \text { separation } \\ \text { Turntable }\end{array} \\ \text { Support storage vessel, guard tank, and interfacing } \\ \text { refueling equipment loads, and transfer these loads } \\ \text { to the vault concrete } \\ \text { Provide for rotational movement and positioning of } \\ \text { the turntable }\end{array}$

Access to the storage positions is obtained through nine fuel transfer ports in the closure head, which are located within the coverage of the EVTM. A cold-wall cooling sleeve is provided around each fuel transfer port in the EVST, to provide emergency cooling in the unlikely event that a CCP containing a spent fuel assembly should become immobilized while passing through the port. A blower is provided to blow building air through the cooling sleeve in such a case.

The turntable is rotated to gain access to each storage position in each row. Rotation is by means of a bearing and two drive assemblies. Pinion gears are driven by speed reducers through a roller chain, and the pinion gears drive the bull gear which is attached to the turntable.

The EVST has three independent and redundant heat removal systems. Any one system is capable of removing the maximum design decay heat.

EVST shielding above the sodium pool consists of 22 in. of steel including the closure head plus 2 in. of borated polyethylene neutron shielding attached under the striker plate. This shielding will assure that the radiation level above the striker plate will not exceed $0.2 \mathrm{mrem} / \mathrm{hr}$ under the design basis condition. 
Argonne

Nuclear Engineering Division

Argonne National Laboratory

9700 South Cass Avenue, Bldg. 208

Argonne, IL 60439-4842

www.anl.gov

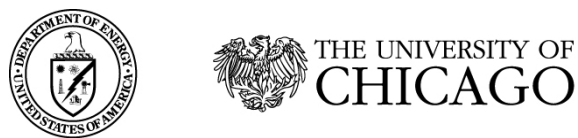

A U.S. Department of Energy laboratory managed by The University of Chicago 